\title{
A stochastic indicator for sovereign debt sustainability
}

\author{
Jasper Lukkezen and Hugo Rojas-Romagosa*
}

15 July 2016

\begin{abstract}
We propose a stochastic indicator to assess government debt sustainability. This indicator combines the effect of economic uncertainty -represented by stochastic simulations of interest and growth rates- with the expected fiscal response that provides information on the long-term country specific attitude towards fiscal sustainability. We apply our framework on post-war data for nine OECD countries and find that our indicator -the potential increase in debt in bad states of the world-distinguishes countries that have sustainability concerns: Italy, Spain, Portugal and Iceland, from those that do not: United States, United Kingdom, Netherlands, Belgium and Germany.
\end{abstract}

Keywords: public debt, fiscal policy, debt sustainability, stochastic simulations JEL Classification: H6, H3, E6

\section{Introduction}

Whether government debt -and fiscal policy in general- is sustainable in the medium and long-term has been one of the main topics of debate in the current Euro crisis. An assessment of debt sustainability is a key input in decisions concerning the speed of fiscal consolidation, the need for reform and the determination of risk premia on government debt. Furthermore, fiscal surveillance is a key concern within a monetary union, where unsustainable public finances may cause significant cross-border spillovers ${ }^{1}$ There is considerable debate, however, on how to measure debt sustain-

*Lukkezen: Utrecht University Kriekenpitplein 21-22, 3584EC Utrecht, The Netherlands (j.h.j.lukkezen@uu.nl) and Economisch Statistische Berichten; Rojas-Romagosa: CPB Netherlands Bureau for Economic Policy Analysis, Postbus 80510, 2508GM The Hague, The Netherlands (h.rojas-romagosa@cpb.nl). Acknowledgements: The authors would like to thank Nico van Leeuwen for excellent research assistance; Oscar Bajo Rubio, Henning Bohn, Frits Bos, Carlos Marinheiro and Jan Luijten van der Zanden for making their data available; and two anonymous referees and the editor of this journal, as well as Leon Bettendorf, Adam Elbourne, Casper van Ewijk, Clemens Kool, Catherine Mathieu, Ruud Okker, Bert Smid, Paul Veenendaal and participants at CPB, UU seminars and the Euroframe 2012 conferences, for providing suggestions for improvement. All errors are our own.

${ }^{1}$ For an overview of direct spillovers see Lejour et al. (2011), for spillovers via contagion see Arezki et al. (2011) and for spillovers via monetary policy see Beetsma and Giuliodori (2010) and references therein. 
ability. The original sustainability norms envisaged at the creation of the European Monetary Union (EMU) were to follow the Maastricht Treaty criteria: ceilings of $3 \%$ and $60 \%$ on government deficits and debt-to-GDP ratios, respectively. However, these criteria have proven to be inadequate as several countries violated these criteria without consequences, while others that met them have been nonetheless hit by the crisis. In particular, Spain had debt-to-GDP ratios and budget deficits well below these Maastricht limits, but has still suffered sovereign debt problems.

The objective of this paper is to find more informative economic indicators that provide guidance on medium- and long-term fiscal sustainability. We develop a dynamic framework for the assessment of sustainability of public finances and focus on the question whether governments can be expected to be "in control" of public finances. Our approach entails a simple and practical stochastic simulation which takes into account the response of fiscal policy to the state of public finances.

Our methodology has two steps. First, we follow Bohn $(1998,2008)$ and estimate a fiscal reaction function (FRF), which provides information on the long-term country-specific behaviour of that country's government and its attitudes towards fiscal sustainability. A positive and significant FRF coefficient denotes a country that has been committed to reduce or maintain steady debt-to-GDP ratios conditional on short-term economic fluctuations and temporary government expenditures ${ }^{2}$ In the second step, the estimated FRF is combined with the stochastic debt simulation method proposed by Celasun et al. (2006) and Budina and van Wijnbergen (2008), which uses historic volatility of interest and growth rates to generate a distribution of future expected debt levels. We then simulate this model ten thousand times to generate a distribution of debt paths, which can be used to analyse the effect of fiscal responses and interest and growth rate volatility on debt-to-GDP ratios $\mathrm{S}^{3}$

The main contribution of this paper is that using this framework we derive a stochastic indicator for the assessment of sustainability of government debt. Our indicator provides insight into the question whether a country is "in control" of its public finances. In practical terms, debt can be regarded as sustainable if it does not lead to ever diverging debt ratios in the long run -i.e. if the simulated debtto-GDP distribution is properly defined and bounded (Hall, 2013). We define our sustainability indicator to assess the upward risk associated with the distribution of the simulated future debt levels. In particular, our indicator measures the devi-

\footnotetext{
${ }^{2}$ In particular, a positive and significant FRF coefficient can be interpreted as a government that engages in fiscal austerity to reduce debt levels even when markets are not specifically concerned about those debt levels, nor is there international pressure (e.g. EU institutions) to reduce them. A reason for engaging in austerity even when not forced might be that fiscally responsible politicians have larger re-election probabilities in advanced economies (Brender and Drazen, 2005, 2008).

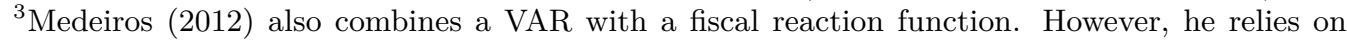
shorter time series and is therefore restricted to estimate a panel fiscal reaction function that yields the average fiscal response. This approach thus has the limitation that it assumes that each country has the same fiscal response, irrespective of institutional settings, policy-maker attitudes towards debt and historical precedents. Berti (2013) uses a VAR to capture the shocks as well, she however has no endogenous fiscal response, yet focuses on incorporating central projections for fiscal policy.
} 
ation of the distribution's upper bound with respect to its median. ${ }^{4}$ Note that we explicitly avoid using any limit or critical debt level as part of our sustainability indicator $5^{5}$ If the upward risk is large -as reflected in our sustainability indicatordefault fears cannot be dismissed as irrational, since after all, the debt level could rise significantly. A stronger FRF limits upward risk and leads to lower indicator values, reflecting the confidence by market participants that the government will take the actions necessary to restore financial stability ${ }^{6}$ Conversely, more volatile interest and growth rates increase upward risk as they lead to more uncertainty.

Given the long-term character of a fiscal response, we collected annual historic data on GDP and government finances for nine OECD countries spanning over a century: United States, United Kingdom, Netherlands, Belgium, Germany, Italy, Spain, Portugal and Iceland. In this paper we focus on the post Second World War period, using the pre-war data as a robustness check. We find that until the 1980s, public debt was reduced by real growth and relatively low -and at times negative- real interest rates. In practical terms, this means that in this period it was not necessary to implement fiscal austerity plans to substantially reduce public debt. With financial liberalisation from the 1980s onwards, however, governments are less capable of controlling real interest rates and this increased the importance of fiscal policy for debt sustainability. We find that for the United States, the United Kingdom, the Netherlands, Belgium and Germany the fiscal response to increases in the debt-to-GDP ratio has been robust and positive for the whole sample as well as the post-war period. On the other hand, Spain, Portugal and Iceland have non-significant fiscal responses in the post-war period, which creates doubts about their capacity to reduce debt by fiscal austerity. Italy has a positive and significant fiscal response coefficient, yet has debt sustainability concerns as its high current debt level makes it very susceptible to fluctuations in interest and growth rates. For instance, the simulated future debt paths for Italy, Spain, Portugal and Iceland show that their larger interest and growth rate variance requires a relatively large fiscal response to prevent debt levels from becoming unsustainable.

Finally, we show that our debt sustainability indicator ("DSI") performs well as an early-warning indicator. When we use only data until 2007 (i.e. prior to the financial crisis), we find that our indicator is highly correlated with sovereign risk

\footnotetext{
${ }^{4}$ For example, if the distribution of the simulated debt levels is relatively wide, then the probabilities of future debt levels to increase substantially are higher than when the distribution is relatively narrow. This upward risk is captured by a higher level of our sustainability indicator. Technically, our indicator is defined as the difference between the $97.5 \%$ upper bound minus the median of the simulated debt distribution. The use of the $97.5 \%$ level is arbitrary, but using values of $95 \%$ and $99 \%$ yield the same qualitatively results.

${ }^{5}$ Several papers find that debt above a certain level has negative consequences for economic growth (Reinhart and Rogoff 2010, Cecchetti et al., 2011, Checherita-Westphal and Rother, 2012, Égert, 2012, Baum et al., 2013). However, the causality between debt and growth is difficult to establish and critical debt levels are generally country-specific (e.g. Japan has debt levels way above any critical level mentioned in the literature, while other countries had debt crisis well below these critical levels), which makes the cross-country results from these studies not informative in an indicator when applied to different countries.

Bursian et al. (2015) study the role of trust on fiscal reaction functions.
} 
premia between 2009 and 2012. Our indicator thus clearly identifies those countries that were later hit by the debt crisis: Portugal, Iceland, Italy and Spain. Moreover, it outperforms market based indicators prior to the crisis such as CDS rates in 2007.

An assessment of debt sustainability using this approach can complement existing indicators. Static sustainability indicators, such as the size of public debt or the budget balance are often used to assess government finances in the short- and medium term (European Commission, 2012b). $]^{7}$ While these indicators are straightforward and unambiguous, they provide little information on the uncertainties public finances face in the near future. Moreover, these indicators neglect the role of the policy maker in controlling public debt. There is ample evidence, however, that the responsiveness of fiscal policy to economic setbacks and the quality of fiscal institutions are essential to debt sustainability. Our approach contributes to this literature by explicitly modelling the effect of economic uncertainty on medium/long term debt sustainability. Nevertheless, it is important to note that our results are not informative over short-term developments. In particular, our analysis is based on ex-post data (at least a year old) that already accounts for any endogenous behaviour between fiscal policy, financial markets and the real economy -but these mechanisms are still at play in any short-term debt sustainability assessment and thus, they are beyond the scope of our analysis 8

The paper is organised as follows. Section 2 presents the theoretical background on debt sustainability. Section 3 describes the data. In Section 4 we elaborate on our empirical strategy and present country-specific econometric results. Section 5 describes our stochastic analysis and Section 6 explains how we construct our debt sustainability indicator and how to apply it as an early-warning indicator. Section 7 summarises our main results.

\section{Fiscal reaction functions and debt sustainability}

We analyse debt sustainability using the approach developed by Bohn (1998, 2008). In essence, Bohn equates fiscal sustainability with the stationarity of the debt-toGDP time series -i.e. when the debt-to-GDP time series is stationary over time, the debt is sustainable. His approach uses historical information on government finances and identifies the channels that determine the path of the debt-to-GDP ratio over time.

Bohn's approach uses two equations to determine the evolution of the debt-toGDP ratio: the accounting equation for debt and a behavioural equation for primary surplus. Both equations are specified with an error-correction for the primary

\footnotetext{
${ }^{7}$ See http://ec.europa.eu/economy_finance/economic_governance/index_en for an overview of European regulations and directives based on such indicators. For the long term, the European Commission employs projections to assess the sustainability of public finances against the background of ageing populations (European Commission, 2012a).

${ }^{8}$ Readers interested in short-term behaviour should use indicators from the signals approach (Berti et al. 2012) or resort to structural modelling.
} 
surplus-to-GDP ratio and the debt-to-GDP ratio. First, the accounting equation:

$$
d_{t+1}=\frac{1+r_{t}}{1+y_{t}}\left(d_{t}-s_{t}\right)
$$

which says that the debt-to-GDP ratio at the beginning of period $t+1, d_{t+1}$, equals the debt-to-GDP ratio at the beginning of period $t$ minus the primary surplus-toGDP ratio over period $t, s_{t}$, times the gross interest rate factor over period $t, 1+r_{t}$, divided by the change in the GDP over period $t, 1+y_{t} \cdot 9$ For our analysis we use real growth and interest rates 10

Second, we estimate a behavioural equation for the primary surplus-to-GDP ratio, which tells us how the government's budget responds to debt accumulation given a structure of shocks occurring in the background. We estimate the following regression:

$$
s_{t}=\alpha+\rho d_{t}+\beta \mathbf{Z}_{t}+\varepsilon_{t},
$$

where $\rho$ is the fiscal reaction parameter, which indicates whether the government has increased its primary surplus as a reaction to an increase in the debt-to-GDP ratio, $\mathbf{Z}$ is a set of other primary surplus determinants and $\varepsilon_{t}$ is an error term. We will refer to this equation as the fiscal reaction function (FRF) ${ }^{11} \|^{12}$

The use of $\mathbf{Z}$ is crucial to account for shocks and it consists of two variables: YVAR, a measure of cyclical fluctuations in output (e.g. business cycles); and GVAR, a measure of temporary government spending (e.g. military expenditure during war periods) 13 The presence of these shocks makes it difficult to detect if $d$ is stationary. Including these variables, hence, is crucial for the results (Bohn. 1998) 14

\footnotetext{
${ }^{9}$ Throughout this paper stock variables are defined at the beginning of the period, whereas flow variables are defined over the period. Interest rates refer to effective interest rates defined as the proportion of interest payments to the overall government debt level.

${ }^{10}$ We could have used nominal growth and interest rates as well. Note that the nominal interest rate is given by $i=(1+r)(1+\pi)-1$ with $\pi$ inflation, and the nominal GDP growth rate is given by $g=(1+y)(1+\pi)-1$. In equation (1) they cancel out to the first order.

${ }^{11}$ Note that it is also possible to postulate an auto-regressive process for $s_{t}$, as in Bartoletto et al. (2013). Then the actual fiscal response is captured by a combination of an auto-regressive and a response to debt parameter. We prefer to stay as close as possible to Bohn's approach and proceed by calculating our fiscal response using autocorrelation consistent estimators in Section 4 .

${ }^{12}$ There is a potential bias in equation 2, which is of limited consequence. If the debt-to-GDP ratio has a unit root, the estimated fiscal response coefficient will be biased downwards towards zero. Then, the parameter $\delta$ (to be introduced later) will be biased upwards and we will conclude with even more certainty that debt is not sustainable. If the debt-to-GDP ratio does not have a unit root, our results are unbiased and this does not matter. We added text to bring this point across.

13 Bohn (1998) uses Barro (1979)'s classical tax-smoothing theory to underpin the use of these variables as temporary government expenses and the effects of business cycle slow-downs should be financed by a higher budgetary deficit.

${ }^{14}$ From our empirical estimations, however, we find that the crucial variable is YVAR. In our sensitivity analysis, when we drop GVAR and use only YVAR, our main results hold (see Section 4.4. Moreover, our results are also robust to the use of lagged YVAR and GVAR variables to control for an unknown form of endogeneity in Equation 2
} 
Substituting equation (2) in (1) yields an expression for the evolution of the debt level:

$$
d_{t+1}=\gamma_{t}(1-\rho) d_{t}-\gamma_{t}\left(\alpha+\beta \mathbf{Z}_{t}+\varepsilon_{t}\right),
$$

where $\gamma$ summarises the relationship between interest rates, growth rates and inflation:

$$
\gamma_{t}=\frac{1+r_{t}}{1+y_{t}}
$$

As $E\left(\mathbf{Z}_{t}\right)=0$, debt sustainability becomes a function of $\gamma$ and $\rho$. When we use average values for interest and growth rates ( $\bar{r}$ and $\bar{y}$, respectively), we can summarise this information using the parameter $\delta$, such that:

$$
\delta=\bar{\gamma}(1-\rho)=\frac{1+\bar{r}}{1+\bar{y}}(1-\rho)
$$

We distinguish three cases:

- $\delta<1$ implies stationary debt-to-GDP ratios 15

- $\delta>1$ but with $0<\rho<\bar{r}-\bar{y}$ implies mildly explosive paths for debt-to-GDP ratios (but growing slowly enough to be consistent with IBC) ${ }^{17}$

- $\delta>1$ with $\rho<0$ and $\bar{r}-\bar{y}>0$ characterises exponentially growing debt.

We require, following Bohn (1998, 2008) and Ghosh et al. (2013), a stationary process for the debt-to-GDP ratio - thus $\delta<1$. By doing so, we deviate from the literature that uses unit root or cointegration tests to test whether the intertemporal budget constraint (IBC) holds 18 As the intertemporal budget constraint holds whenever there is any corrective action $(\rho>0)$, a mildly explosive debt path is not ruled out. This can be problematic as a mildly explosive debt path implies a mildly explosive path for the fiscal response ( $\rho$ times $d$ ) and hence primary surplus as well (Bohn, 2007).

Requiring a stricter condition on sustainability makes the features of the FRF test not less convenient. Mendoza and Ostry (2008) describe in detail the benefits and limitations of the FRF analysis. First, it does not require knowledge of the

\footnotetext{
${ }^{15}$ Bohn (1998) argues that the coefficient estimates of equation 2 are unbiased if $\delta<1$. He assumes that $\bar{\gamma}$ and $\alpha+\beta \mathbf{Z}_{t}+\varepsilon_{t}$ are stationary and states that if $(1-\rho) \bar{\gamma}<1$ then $d$ should be stationary. If $d$ is stationary, the debt-to-GDP ratio follows a auto-regressive process with near unit root behaviour and OLS coefficient estimates are unbiased. If $(1-\rho) \bar{\gamma}>1$, estimates of $\rho$ may be biased towards zero, which makes debt look even more non-stationary.

${ }^{16}$ The deterministic steady state debt level can be obtained by writing equation (3) in first differences:

$$
\Delta d_{t+1}=-(1-\delta) d_{t}-\bar{\gamma} \alpha
$$

where we use that, by construction, $E\left(\mathbf{Z}_{\mathbf{t}}\right)=E\left(\varepsilon_{t}\right)=0$. Then the deterministic steady state yields $\bar{d}=(1-\delta)^{-1} \bar{\gamma} \alpha$.

${ }^{17} \mathrm{See}$ Bohn (2007) for a formal proof. At the boundary between the first and the second case lies a difference-stationary debt (this is the most studied scenario in the unit root literature).

${ }^{18}$ See Afonso (2005) for a survey of these type of studies.
} 
specific set of government policies on debt, taxes and expenditures. The FRF test determines whether the outcome of a given set of policies implicit in the past primary balance and debt data is in line with fiscal solvency, without knowing the specifics of those policies. Second, since asset pricing applies to all kinds of financial assets, the analysis does not require particular assumptions about debt management, or the composition of debt in terms of maturity or denomination structure. Third, it relies entirely on ex-post realisations of all our variables. This means that it already contains the outcomes of the endogenous process that interacts governmental policies, financial market assessments and the response of the real economy in the short-run.

A final remark concerning the FRF analysis is that a time-invariant conditional response of the primary balance to the debt level $(\rho)$ alone is a sufficient but not a necessary condition for debt sustainability. A non-linear and/or time varying response can also generate fiscal solvency as long as the response is strictly positive above a certain debt-to-GDP threshold ratio. This implies that countries without a positive $\rho$ and with $\gamma>0$ do not necessarily have unsustainable government finances. Theoretically, they could have a response that kicks in at some higher, not yet reached, debt level or specific set of government policies that will likely improve primary surplus in the future. In practical terms, this refers to non-linear relationships in equation (2), for which we test in our empirical analysis.

What does this analysis tell us about the channels through which the debt level is controlled? From equation (4) we see that the evolution of the debt ratio is driven by three contributing channels:19

1. Fiscal reactions. These are captured by the estimated coefficient $(\rho)$ of the FRF and provide information on the historical fiscal reaction of governments (i.e. changes in primary surpluses) to changes in the debt-to-GDP ratio. A positive and significant FRF coefficient denotes a country that has been historically committed to reduce or maintain steady debt-to-GDP ratios conditional on short-term economic fluctuations and temporary government expenditures (e.g. military expenditures during wars) ${ }^{20}$ The estimated FRF coefficient is a long-term country-specific institutional indicator that provides information on the fiscal behaviour of that country's government and its attitudes towards fiscal sustainability ${ }^{21}$

2. Real growth dividend. This term has a beneficial effect on the debt-to-GDP ratios when real GDP growth $(y)$ is positive and sustained over time. There-

\footnotetext{
${ }^{19}$ We depart slightly from Bohn's classification, who defined "growth dividend" as the difference between real interest rates on government debt and real GDP growth rates.

${ }^{20}$ For instance, in terms of the recent Euro crisis, a positive FRF coefficient can be interpreted as a government that engages in fiscal austerity to reduce debt levels even when fiscal policy is not pro-cyclical, or markets are not specifically concerned about those debt levels, nor is there international pressure (e.g. EU institutions) to reduce them.

${ }^{21} \mathrm{~A}$ probable reason why these fiscal reactions could be persistent is that in advanced economies fiscally responsible politicians at the national level have larger re-election probabilities (Brender and Drazen, 2005, 2008).
} 
fore, this term groups governmental policies - such as structural reforms- and external factors - such as technological innovations- on the real economy that have a medium- to long-term effect on real growth rates.

3. Real effective interest rates $(r)$ on government debt. This is the difference between the nominal interest and the inflation rate. Thus, this category groups the monetary and financial policy instruments available to governments to reduce debt levels.22

If economic growth $y$ is larger than the effective interest rate $r$, then $\gamma<1$ and the debt-to-GDP ratio decreases over time and a positive fiscal response is not needed to assure debt sustainability. This is also known as the "Aaron condition" (Aaron, 1966). If this condition is not met (e.g. $y<r$ and thus, $\gamma>1$ ) then debt sustainability depends on the fiscal reaction function: primary surpluses should be sufficiently responsive to the debt-to-GDP ratio to arrive at a stationary debt-toGDP level.

\section{Data}

We analyse countries with historical time series of at least 70 years. ${ }^{23}$ The countries in our sample are: the United States (USA), the United Kingdom (GBR), the Netherlands (NLD), Belgium (BEL), Germany (DEU), Italy (ITA), Spain (ESP), Portugal (PRT) and Iceland (ISL). Long-time series are necessary as reliable estimates of the FRF should span several business cycles and contain periods of increasing and decreasing debt levels.

As most countries were affected significantly by the Second World War, the end of the war provides a natural starting point for our main sample. ${ }^{24}$ In this period, our estimations can be directly related to the current institutional settings in our nine OECD countries. Thus, using the post-war sample we can abstract from considering other institutional settings that may have been present if we used the full historical sample -that includes data as far back as 1691 for the United Kingdom. Therefore, we only use the full-sample results as a robustness check for the post-war sub-sample.

We use the following time series: nominal GDP, real GDP, GDP deflator, gross debt, primary surplus, interest payments on gross debt and government expenditures 25 YVAR is obtained from the real GDP series and GVAR from government

\footnotetext{
${ }^{22}$ These policies are also linked to the term "financial repression" coined by Reinhart and Sbrancia (2011), who define it as policies that depress real interest rates -while the extreme case of periods with negative real interest rates is defined as "liquidation years".

${ }^{23}$ With the exception of Germany, for which we only have complete data from 1970 onwards.

${ }^{24}$ The exact initial year of the sample varies between countries because of particular data limitations.

${ }^{25}$ The last variables are all in nominal terms.
} 
expenditures as a percentage of GDP. The sources and the assumptions we made while preprocessing the data are fully described in Appendix $\mathrm{C}^{26}$

In Figure 1 we show the debt level per country in the post-war sample. Five countries: the United States, the United Kingdom, the Netherlands, Belgium and Spain begin with high debt levels after the Second World War. These levels declined sharply afterwards, but have increased again in the later period -especially in the last decade. The other countries: Germany, Italy, Portugal and Iceland began the period with relatively low debt levels and have experienced steady debt increases.

As is shown in Figure 6 in the Appendix real growth rates have declined on average for all countries since the Second World War. Italy, Spain and Portugal, however, experienced a growth boom in the 1960s, while Iceland did so in the late 1970s. To identify periods with low real interest rates, Figure 7 in the Appendix plots nominal interest rates against inflation (estimated from the GDP deflator). Low real interest rates were experienced in all countries until at least the 1980s and was largest for Iceland, Italy, Portugal and Spain. This is consistent with the findings in Reinhart and Sbrancia (2011).

Figures 8 to 12 in the Appendix show the time series for the debt-to-GDP ratio, the primary surplus to GDP ratio, and $\gamma$ per country for the post-war sample. In addition, we show the military expenditure for the US and the UK.

Finally, Table 3 in the Appendix shows the results of standard unit root tests. They confirm our expectations from the previous section: the presence of a unit root is firmly rejected in primary surplus, YVAR and GVAR for most countries, yet cannot be ruled out in the debt-to-GDP time series. This is a result of the low power of standard unit root tests in distinguishing unit root from near unit root processes.

\section{Estimating fiscal reaction functions}

Our empirical strategy is straightforward and consists of two main components. First, we estimate equation (2) for all countries to obtain the fiscal response parameter $\rho$. Second, we calculate the average values for the real interest rates and real growth rates and use these values to obtain $\gamma$. With both sets of information we then estimate $\delta$ as defined in equation (4). Using this information we analyse if government finances have been sustainable and if it was due to prudent fiscal policy, low real interest rates or the growth dividend.

We also tried a panel analysis. However, this approach is highly problematic. First, we find them non-informative due to large cross-country heterogeneity in response to fiscal policy, business cycles and temporary expenditure spells. Second, the results yield a country-average assessment of debt sustainability, while debt sustainability concerns are mainly country-specific.

\footnotetext{
${ }^{26}$ Table 14 presents a short summary of the available data. Furthermore, unit root tests reject the presence of a unit root for all variables, except the debt-to-GDP ratio series. This is however closely related to the topic of the paper and treated extensively in Section 2
} 
Figure 1: Debt-to-GDP ratios in the post-war period.
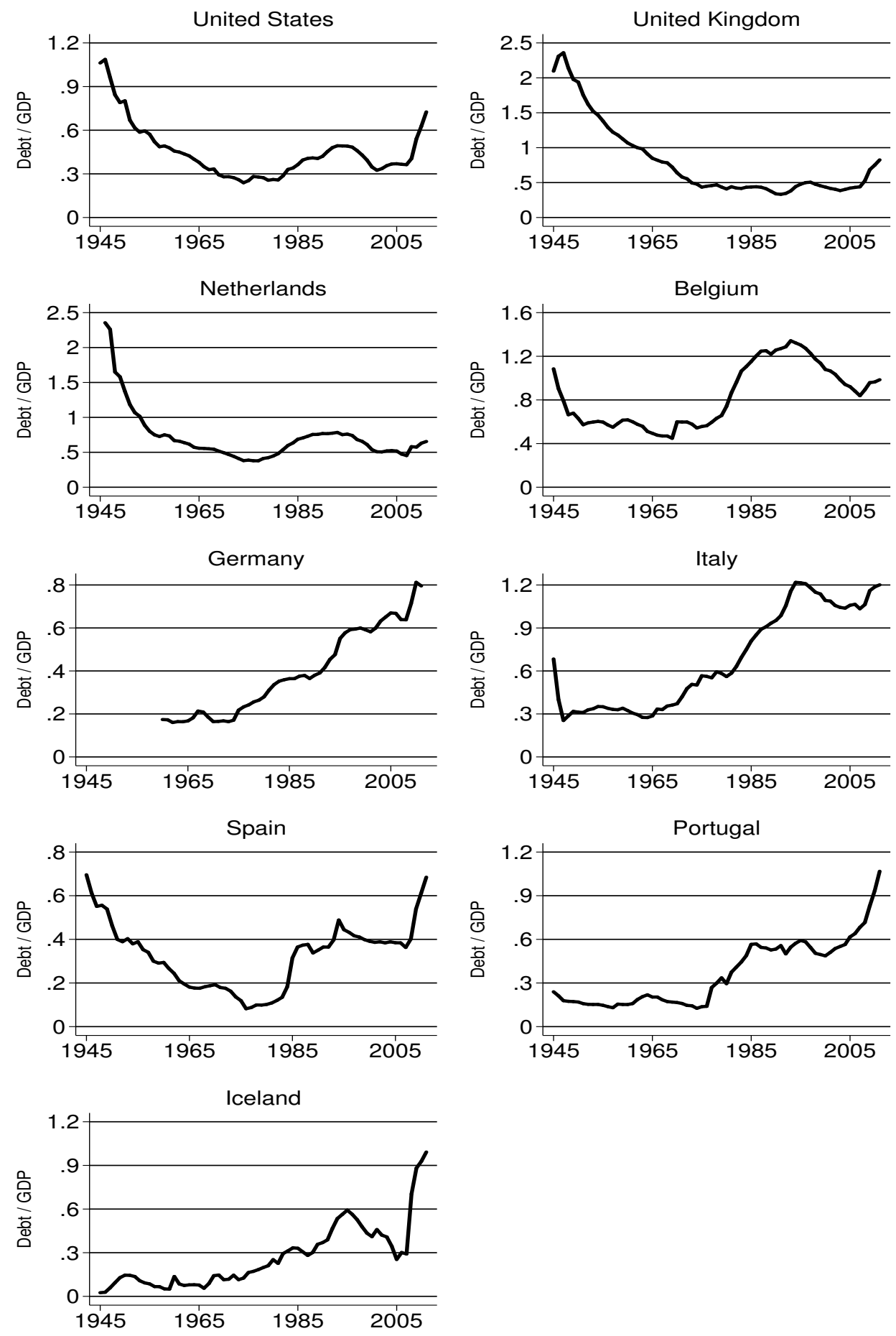

Notes: Data sources are provided in the online Appendix. 


\subsection{Linear regressions}

The fiscal response coefficients are estimated on the post-war period using both OLS and autocorrelation and heteroskedasticity consistent estimators. As control variables we use the indicator of fluctuations in income growth (YVAR) and fluctuations in government expenditures (GVAR), given the importance of these two variables for the analysis (cf. Bohn, 1998), 27

Analogous to Bohn (2008), we use an HP-filter $(\lambda=100)$ to extract the trend component of log real GDP and define YVAR as the gap between the actual value and this trend in percentage points of GDP ${ }^{28}$ We extract GVAR analogously to YVAR by using the cyclical component of government spending ${ }^{29}$ These linear multivariate regressions are the core of our empirical analysis, but we check the robustness of these results in Section 4.4.

\subsection{Non-linear regressions}

We also examine whether the response of the primary surplus to an increase in the debt-to-GDP ratio is non-linear. There are different ways, however, to interpret these non-linearities. On one hand, non-linearities may arise because -above a certain debt-to-GDP ratio- the incentives for policy makers to increase the primary surplus are missing, causing a debt overhang problem. This concept was introduced by Krugman (1988) and confirmed empirically by Callen et al. (2003) and Mendoza and Ostry (2008) for emerging market economies. On the other hand, non-linearities may arise because policy makers get increasingly nervous about the possibility of losing access to capital markets. In that case there are larger fiscal responses at higher debt levels. For instance, high debt levels can raise financing difficulties for the government. Bohn (1998, 2008) finds that for the United States the conditional response of primary surplus to debt is stronger when the debt-to-GDP ratio is high by historical standards. In their recent study on fiscal space Ghosh et al. (2013) combine both views.

We test for non-linearities using two approaches. First, we add the quadratic terms: $d_{t}^{2}$ and $\left(d_{t}-\bar{d}\right)^{2}$ as explanatory variables in equation $(2)$, where $\bar{d}$ is the mean value of $d$. Second, we examine if the fiscal response is different above a certain level of debt-to-GDP. To test this we create three dummy variables: $d \max , d_{\text {max }} 40$ and $d \max _{60}$, where $d \max =1$ if the debt-to-GDP ratio is above the historical debt average, and otherwise $d \max =0$. Accordingly, $d \max _{40}$ and $d_{\max } 60$ are equal to one if $d$ is above $40 \%$ and $60 \%$, respectively. We add each additional variable separately in equation (2), but only present the results for $d_{t}^{2}$ and $d_{\max }$.

\footnotetext{
${ }^{27}$ The univariate regressions are available upon request.

${ }^{28} \mathrm{~A}$ more structural way is to estimate potential GDP first and then define the difference between actual and potential GDP as the output gap. This is used by the OECD (2005). We do not apply this method due to data limitations. However, the HP-filter generates an output gap comparable to those in OECD (2005), so the potential measurement error is small.

${ }^{29}$ Mendoza and Ostry (2008) also use this approach. Their results are robust to different specifications for extracting the cyclical component.
} 


\subsection{Econometric results}

The country-specific results are summarised in Table 1. The upper part of this table presents a summary of the regression results in Tables 5 to 13 in the Appendix. For the United States (USA), the United Kingdom (GBR), the Netherlands (NLD), Belgium (BEL), Germany (DEU) and Italy (ITA) the fiscal reaction coefficient $(\rho)$ is positive and significant for the post-war sample ${ }^{30}$ This shows that these governments have significant and strong fiscal responses to increases in the debt-to-GDP ratio, once we control for the business cycle (YVAR) and temporary expenditures (GVAR). On the other hand, Spain (ESP), Portugal (PRT) and Iceland (ISL) do not have significant fiscal reaction coefficients, and it is even negative for the last two countries.

Furthermore, when using non-linear specifications we find that for the United States, the Netherlands, Belgium and Italy the response to square debt is positive and significant. This means that these governments have a stronger fiscal response when debt-to-GDP ratios are above their historical average. Contrastingly, the nonlinear coefficients are negative and significant for Germany, Spain, Portugal and Iceland, which creates additional concerns about the debt sustainability of these countries.

The lower part of Table 1 presents the average value of real interest and growth rates and provides our summary parameters: $\gamma$ (i.e. the Aaron condition) and $\delta$ (which combines the Aaron condition with fiscal reaction coefficient $\rho$ ) for three different time periods. Recall that the Aaron condition $(\gamma<1)$ can be satisfied with low (or negative) real interest rates, the growth dividend, or a combination of both and that government finances are deemed sustainable if $\delta=\gamma(1-\rho)<1$.

The Aaron condition is satisfied -on average- for all countries in the post-war period, except for Belgium and Germany ${ }^{31}$ However, since Belgium and Germany have a sufficiently positive and significant fiscal reaction coefficient $(\rho)$, their $\delta$ parameter is below one and government finances are deemed sustainable. This applies to all other countries on average in the post-war period too. However, there is a structural change for most countries at the end of the 1980s. We chose the year 1987 as the break point of the series for illustrative purposes, these results do not depend on the exact year that is chosen. For Italy and Spain we find negative real interest rates until the late 1980s. After 1987 interest rates have large average values well above their average growth rates and thus, both countries do not satisfy the Aaron condition any longer. This combination of higher interest rates and lower growth after 1987 also applies to the United States, the United Kingdom, the Netherlands, Belgium and Germany. On the other hand, Portugal and Iceland still had relatively

\footnotetext{
${ }^{30}$ The policy response of the United States decreases significantly when 2010 and 2011 are included in our estimations. This may imply a structural break in the fiscal stance towards debt or it may indicate that the US government has a delayed response to debt increase which has yet to materialise. However as the fiscal response from the longer historical time series 1792-2011 equals the response from 1948-2009 (compare columns 1 and 7 in Table 5 in the Appendix), we prefer long-term fiscal responses to short-term variations at the end of the sample and choose to restrict our sample.

${ }^{31}$ Bohn (2011) also finds that $\gamma<1$ for the US.
} 
Table 1: Summary of estimated coefficients, average values and the $\delta$-parameter, for all countries in the post-war and sub-samples.

\begin{tabular}{|c|c|c|c|c|c|c|c|c|c|}
\hline & USA & GBR & NLD & BEL & DEU & ITA & ESP & PRT & ISL \\
\hline & $\begin{array}{r}1948- \\
2009\end{array}$ & $\begin{array}{r}1946- \\
2011\end{array}$ & $\begin{array}{r}1948- \\
2011\end{array}$ & $\begin{array}{r}1955- \\
2011\end{array}$ & $\begin{array}{r}1970- \\
2011\end{array}$ & $\begin{array}{r}1948- \\
2011\end{array}$ & $\begin{array}{r}1946- \\
2011\end{array}$ & $\begin{array}{r}1945- \\
2011\end{array}$ & $\begin{array}{r}1946- \\
2011\end{array}$ \\
\hline \multicolumn{10}{|c|}{ Estimated coefficients from linear regressions: } \\
\hline$\rho$ & $0.078 * * *$ & $0.045 * * *$ & $0.078 * * *$ & $0.038 * * *$ & $0.026 *$ & $0.073 * * *$ & 0.005 & -0.005 & -0.020 \\
\hline YVAR & $0.284 * *$ & 0.410 & $0.451 * * *$ & $0.612 * * *$ & $0.227 * *$ & 0.360 & $0.298 * *$ & 0.053 & $0.203 * *$ \\
\hline GVAR & -0.083 & -0.143 & 0.046 & $-0.101 * * *$ & $-0.260 * * *$ & -0.039 & -0.039 & -0.048 & $-0.093 * * *$ \\
\hline \multicolumn{10}{|c|}{ Estimated coefficients from non-linear regressions: } \\
\hline$d^{2}$ & $0.238 *$ & 0.021 & $0.158 * * *$ & $0.153 *$ & $-0.196 * * *$ & $0.370 * * *$ & $-0.820 * * *$ & -0.106 & $-0.114 * *$ \\
\hline$d \max _{60}$ & $0.044 *$ & -0.037 & -0.019 & -0.038 & $-0.022 * *$ & $0.125 * * *$ & $-0.120 * * *$ & $-0.050 * * *$ & $-0.050 * * *$ \\
\hline \multicolumn{10}{|c|}{ Average values, full post-war sample (varies by country): } \\
\hline $\bar{r}$ & 0.022 & 0.015 & 0.022 & 0.042 & 0.036 & -0.004 & 0.001 & -0.036 & -0.054 \\
\hline $\bar{y}$ & 0.032 & 0.022 & 0.035 & 0.028 & 0.021 & 0.036 & 0.042 & 0.037 & 0.053 \\
\hline $\bar{\gamma}$ & 0.991 & 0.993 & 0.988 & 1.014 & 1.014 & 0.961 & 0.960 & 0.929 & 0.898 \\
\hline$\delta$ & 0.913 & 0.948 & 0.911 & 0.975 & 0.988 & 0.891 & 0.960 & 0.929 & 0.898 \\
\hline \multicolumn{10}{|c|}{ Average values, post-war until 1986: } \\
\hline $\bar{r}$ & 0.013 & 0.003 & 0.008 & 0.043 & 0.025 & -0.026 & -0.044 & -0.056 & -0.093 \\
\hline $\bar{y}$ & 0.036 & 0.023 & 0.042 & 0.034 & 0.025 & 0.051 & 0.049 & 0.045 & 0.069 \\
\hline $\bar{\gamma}$ & 0.978 & 0.980 & 0.968 & 1.009 & 1.000 & 0.927 & 0.912 & 0.903 & 0.848 \\
\hline$\delta$ & 0.902 & 0.936 & 0.892 & 0.970 & 0.974 & 0.859 & 0.912 & 0.903 & 0.848 \\
\hline \multicolumn{10}{|c|}{ Average values, 1987-2011: } \\
\hline $\bar{r}$ & 0.037 & 0.035 & 0.044 & 0.042 & 0.042 & 0.033 & 0.073 & -0.001 & 0.010 \\
\hline $\bar{y}$ & 0.025 & 0.021 & 0.024 & 0.021 & 0.019 & 0.013 & 0.031 & 0.025 & 0.028 \\
\hline $\bar{\gamma}$ & 1.011 & 1.013 & 1.020 & 1.021 & 1.024 & 1.020 & 1.041 & 0.974 & 0.983 \\
\hline$\delta$ & 0.932 & 0.968 & 0.940 & 0.982 & 0.997 & 0.945 & 1.041 & 0.974 & 0.983 \\
\hline
\end{tabular}

Notes: The full regression results are shown in Tables 5 to 13 in the Appendix. Significance levels: *** $\mathrm{p}<0.01,{ }^{* *} \mathrm{p}<0.05,{ }^{*} \mathrm{p}<0.1$ (computed using heteroskedasticity- and autocorrelation-consistent standard errors with Newey-West lag window of size 1). Dependent variable is the primary surplus to GDP ratio. Explanatory variable YVAR is the gap between log real GDP and its trend and GVAR is the gap between log of government expenditures and its trend for all countries but the USA and GBR (for which "gvar" equals military expenditure). Both trends are extracted using an HP-filter (lambda=100). $d^{2}$ is the square of the debt-to-GDP ratio $(d)$ and $d m a c_{60}$ is a dummy variable equal to one if $d$ is above $60 \%$. Average values for the real interest $(\bar{r})$ and real growth rates $(\bar{y})$ come from Appendix $\mathrm{C} \delta$ parameters are all calculated using the full-sample estimated $\rho$ values when significant.

low real interest rates well into the 2000s. This means that for both countries debt in the post-war period was made sustainable as a result of low or negative real interest rates (for part or the whole period), and thus, strong fiscal responses were not required.

The post-war results do not ensure that debt is or will be sustainable in the near future for these countries. In particular, since the period with low real interest 
rates ended, the importance of fiscal responses has greatly increased. Countries that lack a significant fiscal response may then have difficulties to maintain debt-toGDP ratios at sustainable levels. Moreover, the absence of a linear fiscal response, in conjunction with a negative non-linear response for Germany, Spain, Portugal and Iceland rises the concern that debt may not be sustainable in these countries. Our stochastic analysis in Section 6 will use this information combined with a VAR analysis to provide our early-warning sustainability indicator.

\subsection{Sensitivity analysis}

In this section we test the robustness of our econometric results and present the outcomes per country in Tables 5 to 13 in the Appendix.

First, we employ alternative definitions of GVAR, for some countries, and YVAR for all countries. For the United States and the United Kingdom -where military spending has been historically a big driver of temporary government spending- we define GVAR as the military spending-to-GDP ratio ${ }^{32}$ For the Netherlands we use gas revenue as a proxy for GVAR following Wierts and Schotten (2008). Moreover, we run the regressions without any GVAR term (only YVAR) and the estimated $\rho$ values remain significant (with the exception of Germany) and with qualitatively similar values. For YVAR we employ instead of the difference of actual real GDP from a trend extracted by an HP-filter the difference of actual real GDP from a moving average of 8 years, where assess a mid-point moving average, which uses 3 years prior to the current year, the current year and four years after, and an end-point moving average, which uses the previous 8 years and corrects for average growth. In the last case the fiscal response increases significantly for Belgium and Italy.

Second, we include the real interest rate as an explanatory variable in equation (2). The intuition is that the primary surplus can also react to changes in real interest rates. For instance, when governmental policies generate negative real interest rates (e.g. through financial repression) the government faces less pressure to reduce the debt with fiscal responses. Also, high real interest rates can force the government to apply fiscal austerity, even when the debt-to-GDP level is not that high. For the United States, Bohn (1998) found that interest rates are not a significant control variable. We find similar results for all countries but Germany, where the inclusion of the real interest rates yields a non-significant $\rho$ parameter. We also include inflation as an additional variable as high inflation allows for a less responsive fiscal policy. Inflation turns out to be insignificant in most cases, and when it is significant it does not change the fiscal response parameter.

Third, we assess the stability of the fiscal response over time. The most obvious choice is to include the full historical sample available and not only the post-war

\footnotetext{
${ }^{32}$ This is comparable to Bohn $(2008)$ who defines GVAR as the gap between a permanent component of military outlays to GDP from an estimated $\operatorname{AR}(2)$ process and the actual values. Our approach probably overestimates temporary military spending by a constant term, which likely has no impact on our estimate of $\rho$.
} 
period. These results are presented in the penultimate column of the country-specific Tables in Appendix B -except for Germany for which we do not have data before 1970. It is remarkable that for the United States and the United Kingdom, the fullsample historical fiscal reaction coefficient is significant and very close in value to the post-war estimation. For the Netherlands and Belgium the full-sample coefficient is significant but has a lower value. While for Italy and Spain the significance of the coefficients for both samples is reversed. In Italy $\rho$ is significant in the post-war sample, but it is not significant in the full-sample, while in Spain only the historical $\rho$ coefficient is significant. Portugal and Iceland have non-significant coefficients for both samples. We also used Bai and Perron (1998, 2003) tests for endogenous structural breaks after the Second World War. The resulting sub-samples, however, are usually too short to estimate a stable fiscal reaction function that can assess the long-run institutional stance towards fiscal sustainability. ${ }^{33}$ In that case $\rho$ picks up short-term policy fluctuations and is not suitable for our analysis. The same logic applies when dropping an arbitrary post-war sub-sample. In developing our early-warning indicator we estimated our FRF for a post-war sample that ends in 2007 , instead of 2011. This specification intends to eliminate the possible effects of the current financial crisis on our estimations. We find that for only three countries the significance of the $\rho$ parameter is changed: Spain has now a highly significant $(p<0.01)$ coefficient of 0.07 , Portugal has a lower significant $(p<0.1)$ coefficient of 0.02 , and the significance level of the German coefficient is increased.

Fourth, to assess the impact of potential codeterminacy of the response of primary surplus to debt, the business cycle and temporary government spending, we perform two checks: we use one-year lagged variables for YVAR and GVAR and we estimate our regression with GMM with lags of debt, YVAR, GVAR, primary surplus, inflation, real growth rates and real interest rates as instruments. We find that the $\rho$ coefficient remains robust to this specification. In general, we find it reasonable to expect that the business cycle will be independent of country-specific debt level ${ }^{34}$ In the case of temporary government expenditures, when they are proxied by military expenditure -as in the original FRF estimations for the US by Bohn (1998, 2008) - we also find it reasonable to assume that these are independent of debt levels. When GVAR is estimated as the cyclical component of government expenditure, the case is less compelling. However, as explained above, the use of GVAR as an independent variable is not critical to our estimations of the $\rho$ coefficient.

Fifth, we check whether there is a delay in the response of fiscal policy to debt might have a downward bias on our fiscal response functions by including lagged primary surplus. The total effect is than the coefficient of the response of debt divided by one minus the coefficient of lagged primary surplus. The results are very

\footnotetext{
${ }^{33}$ In addition, these shorter samples are sensitive to specific political events that affected government behaviour in the period. For instance, the dictatorship years in Spain and Portugal under Franco and Salazar.

${ }^{34}$ Note that this does not mean that in short-term (year-to-year) episodes there might be a causal interplay between both variables. But in our historical long-term analysis we do not expect such an interaction to be problematic.
} 
similar. This can be explained by the fact that the debt ratio is a slow moving variable, which means that the effect of an increase in the debt ratio will persist over time even if the response of primary surplus is small initially. Thus, as in Bohn $(1998,2008)$ we find that OLS estimations of the FRF is a reasonable approach.

\section{$5 \quad$ Stochastic debt sustainability simulations}

The results presented in the previous section are based on the assumption that interest and growth rates are equal to their long-run average. However, interest and growth rates fluctuate over time and this has a significant impact on the evolution of the debt level. Higher interest and growth rate volatility increases the distribution of future debt levels and requires a larger fiscal response to keep government debt under control. For instance, Catão and Kapur (2006) provide evidence that differences in macroeconomic volatility are the key determinant of higher spreads. ${ }^{35}$

To assess this relationship we extend the results from the previous section by simulating future interest and growth rate values, which in turn provide a probability distribution for future debt-to-GDP levels.

Specifically, we insert simulated interest and growth rates, represented by $\hat{\gamma}_{t}$, into equation (3):

$$
d_{t+1}=\hat{\gamma}_{t}(1-\rho) d_{t}-\hat{\gamma}_{t} \alpha
$$

Here we used that by construction $E\left(\mathbf{Z}_{\mathbf{t}}\right)=0$ and $E\left(\varepsilon_{t}\right)=0$. To obtain a path for the public debt level $d_{t}$, we integrate forward equation (5) ${ }^{36}$ The simulated interest and growth rates of every step are obtained from a simple two variable VAR model following Budina and van Wijnbergen (2008). This VAR model captures the historic volatility of interest and growth rates:

$$
\begin{aligned}
\left(\begin{array}{c}
r_{t} \\
y_{t}
\end{array}\right) & =\alpha_{0}+\sum_{j=1}^{T} A_{j}\left(\begin{array}{c}
r_{t-j} \\
y_{t-j}
\end{array}\right)+\eta_{t}, \\
\operatorname{var}\left(\eta_{t}\right) & =\mathbf{V}
\end{aligned}
$$

In this set-up shocks to real interest and growth rates are not correlated over time but are correlated within the same time period. The interest and growth rate themselves are correlated over time and within the same time period due to the auto-regressive specification.

We then run this procedure ten thousand times to obtain a distribution of future debt paths. The set of debt levels from the simulation at time $t+s$ is then the distribution of expected future debt levels at time $t+s$. The shape of the distribution

\footnotetext{
${ }^{35}$ In a related study, Genberg and Sulstarova (2008) show how the right hand tail of the distribution of the debt-to-GDP ratio depends on the second moments (i.e. variability) of macroeconomic variables and then regresses these second moments on interest spreads.

${ }^{36}$ To get debt at time $t+1$-i.e. $d_{t+1}$ - we substitute $d_{t}$ and the interest and growth rates of period $t$ in equation (5). Then, to get $d_{t+2}$, we use the estimated $d_{t+1}$ and the interest and growth rates in period $t+1$ and so on and so forth.
} 
of debt paths is informative on fiscal sustainability. In particular, a narrower distribution indicates greater certainty on future debt levels and characterises a country that is more in control of its finances.

Two main processes influence this distribution. First, higher volatility in interest and growth rates broadens the distribution of future debt levels. Second, a larger fiscal response narrows the distribution. This latter happens because, for $\rho>0$, fiscal policy responds to a deviation in the debt level from its steady state value $\bar{d}$. Then, shocks in interest and growth rates that drive the debt level away from $\bar{d}$ are countered by a fiscal response in the subsequent period(s). Similarly, shocks that drive the debt level towards $\bar{d}$ are mitigated by a smaller fiscal response. This effect is stronger for larger $\rho$. Furthermore, if the fiscal response is too weak or if the volatility of interest and growth rates is too strong, the width of the distribution may grow without bound over time. In this case the distribution is not properly defined (i.e. bounded) and, as Hall (2013) shows, the debt level is not stationary.

Our simulations generate a debt path for the period: 2012-2021. We run the simulation for two scenarios: one with the estimated $\rho$ values (cf. Table 1) and another where we assume no fiscal response, i.e. $\rho=0 .{ }^{37}$ Equation $(6)$ is estimated per country using 1987 as a starting point. We thus do not use the historically low real interest rates period experienced in the preceding decades. In addition, we set the number of lags equal to two in equation $(6) 38$

The simulated distributions of expected future debt levels are shown in Figures 2 to 4 . Note that the left-hand figure always includes a fiscal response $(\rho>0)$. This implies that for those countries with $\rho=0$ : Spain, Portugal and Iceland, we artificially set $\rho=7 \%$ for illustrative purposes. All right-hand figures have $\rho=0$. The debt level is on the vertical axes and time is on the horizontal axis. The black line indicates the median debt level from the simulated distribution, the light orange area contains $90 \%$ of the simulation results and the dark orange area contains the next $5 \%$. The two blue lines are visual aids at the $60 \%$ and the $90 \%$ debt level.

In general, the width of the simulated debt distributions is determined by the variability of the growth and interest rates, while the fiscal reaction $(\rho)$ affects the median of the distribution -although it also has a slightly effect on the width of the distribution.

The debt levels have relatively small $90 \%$ and $95 \%$ confidence bands for the first set of countries: the United States, United Kingdom, Netherlands, Belgium and Germany. For the second group -Italy, Spain, Portugal and Iceland- these confidence bands are larger, due to the larger variability in growth and interest

\footnotetext{
${ }^{37}$ For $\rho=0$ we use $\alpha=\overline{\mathrm{ps}}$ in equation $(5)$, with $\overline{\mathrm{ps}}$ the average primary surplus. This correction prevents a change in the average fiscal stance while making fiscal policy irresponsive to the debt level.

${ }^{38}$ Given the number of observations, we could use one or two lags. We test for the number of lags to include using the Akaike Information Criterion. The differences are small and we chose two for all countries as it allows for richer dynamics. The Cholesky-decomposed covariance matrix of the residuals is given in Table 4. We have tested for autocorrelation in the residuals and were able to reject and tested for stability of the VAR and found that for most countries all eigenvalues are in the unit circle.
} 
rates experienced by these countries. From Figures 3 and 4 it is clear that the imposed value of $\rho=7 \%$ is not sufficiently large for Italy, Spain or Portugal to bring the bandwidth of simulations results to levels comparable with the other countries.

For $\rho=0$ we see that the median debt levels are higher when there is no fiscal response ${ }^{39}$ Furthermore, the width of the distribution slightly increases vis-à-vis $\rho>0$ for all countries. On the other hand, Portugal still has a very explosive debt path even with a positive fiscal reaction coefficient of $\rho=7 \%$. This is due to the large historical Portuguese volatility over real growth and interest rates, which creates large uncertainties and wide confidence bands in our simulations.

Figure 2: Stochastic debt projections for the United States, from 2011 to 2021. $\rho$ denotes the fiscal response.
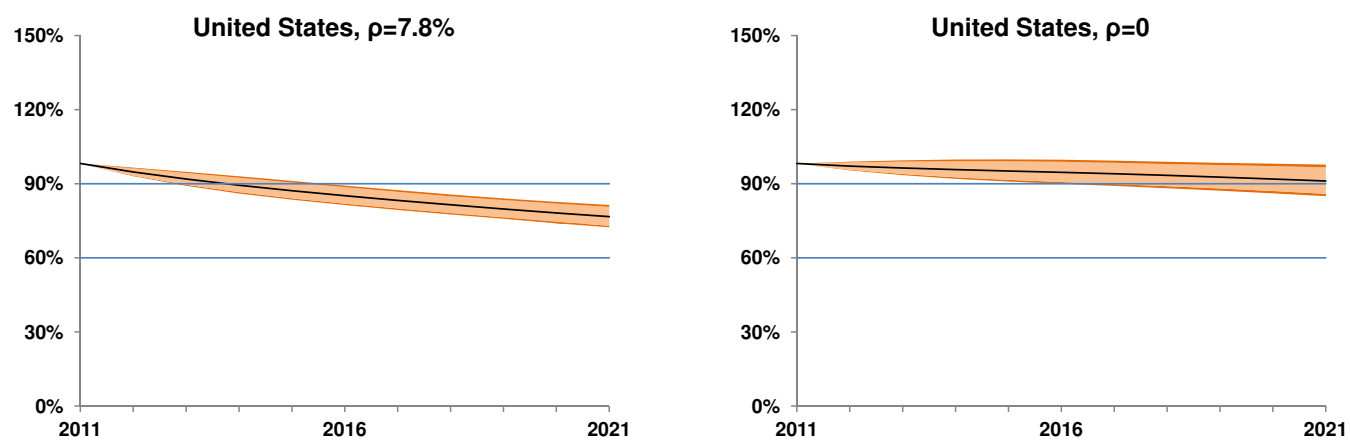

Notes: The dark orange band with $\mathrm{p}<0.95$ encompasses also the light orange band with $\mathrm{p}<0.90$.

\footnotetext{
${ }^{39}$ The Netherlands and Belgium are the exception, because both countries are characterised by a strong fiscal response and a relatively stable debt level (see Figure 1). The fiscal response reacts to both increases and reductions of the debt level from its long-run average, but in the Dutch and Belgian case the latter applies. For instance, the inclusion of the fiscal response "stabilises" the Dutch debt level around its post-war average of $60 \%$, and this results in the projected median debt level being lower with $\rho=0$ than with $\rho>0$.
} 
Figure 3: Stochastic debt projections for the United Kingdom, the Netherlands, Belgium and Germany from 2011 to 2021. $\rho$ denotes the fiscal response.
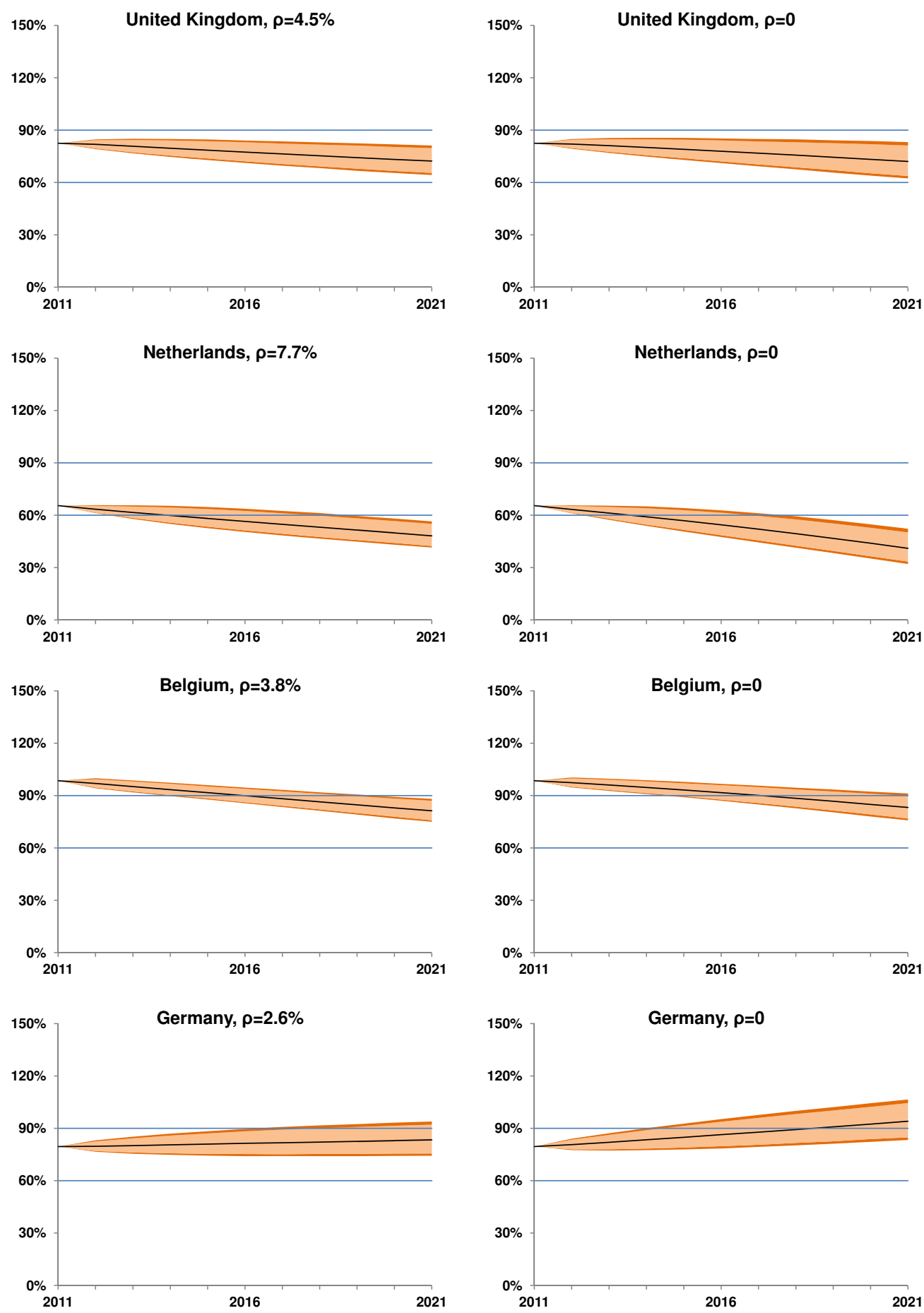

Notes: The dark orange band with $\mathrm{p}<0.95$ encompasses also the light orange band with $\mathrm{p}<0.90$. 
Figure 4: Stochastic debt projections for Italy, Spain, Portugal and Iceland from 2011 to 2021. $\rho$ denotes the fiscal response.
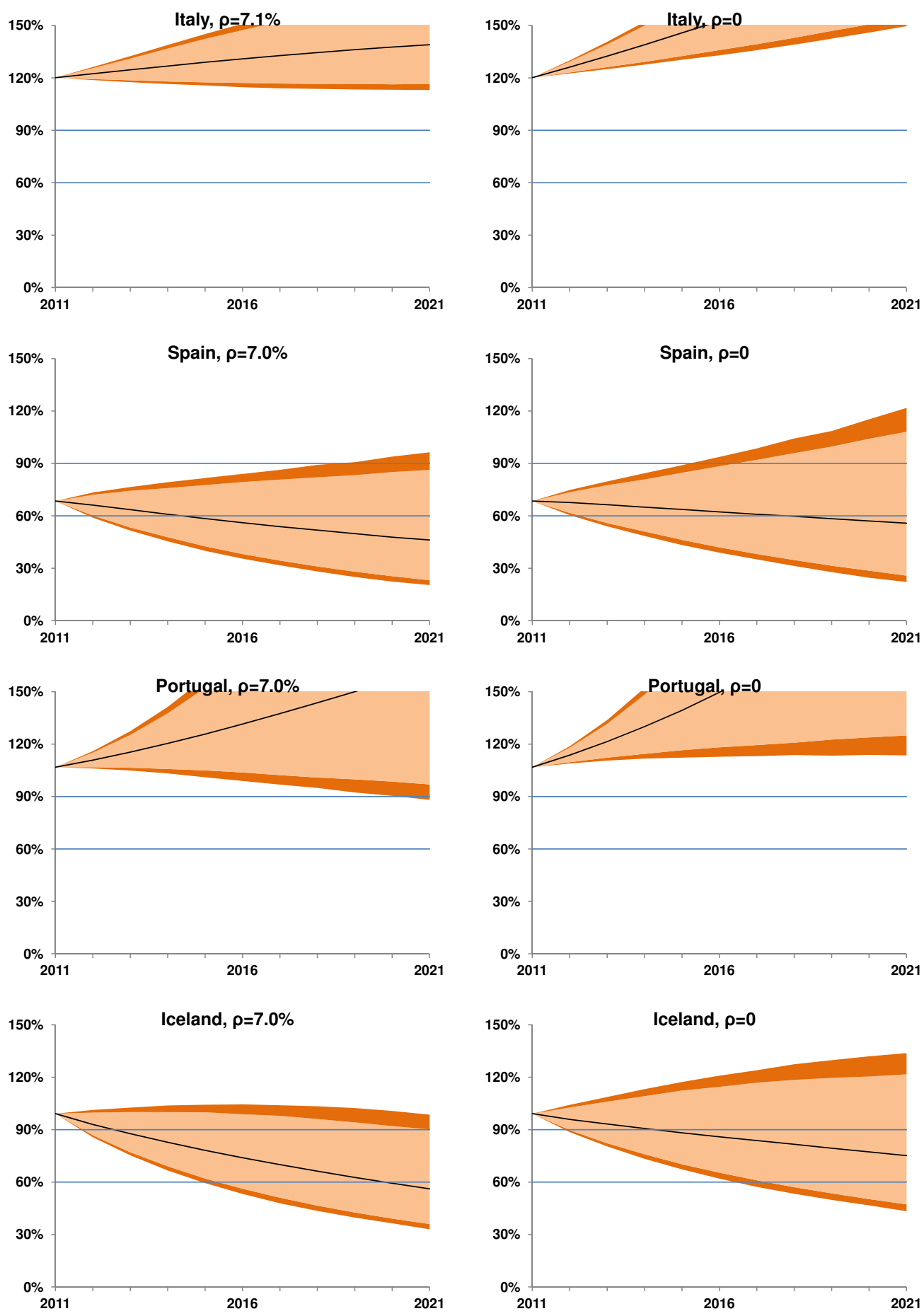

Notes: The dark orange band with $\mathrm{p}<0.95$ encompasses also the light orange band with $\mathrm{p}<0.90$. 


\section{Debt sustainability indicator}

A positive and significant fiscal response has two main effects on our debt projections. First, it directly contributes to a more sustainable fiscal policy by lowering expected future debt levels, which in turn reduces the width of the distribution of debt levels -as the value of the product of deviations in the interest and growth rates with the debt levels is reduced. Second, a stronger fiscal response reduces the impact of the effect deviations in interest and growth rates have on the debt level over time by forcing the debt level towards its steady state. Both effects lead to a narrower distribution of expected future debt levels. We capture this in a Debt Sustainability Indicator (DSI), which is defined as follows:

$$
D S I=d_{t+10}^{97.5 \%}-d_{t+10}^{50 \%}
$$

where $d_{t+10}^{97.5 \%}$ is the 97.5 th percentile of the simulated distribution of $d_{t+10}$ and $d_{t+10}^{50 \%}$ is the median 40 Therefore, our DSI denotes the upward risk of deviating from the median debt level 10 years into the future in our simulation.

Table 2 presents the 2011 debt level, the median 2021 debt level and the value of DSI -both with and without a fiscal response. For the first group of countries: United States, United Kingdom, Netherlands, Belgium and Germany, we find that DSI has low values. In the case of Germany, the fiscal response is crucial in reducing debt. For all five countries, recent low volatility in interest and growth rates yield relatively narrow confidence bands. For the second group of countries: Italy, Spain, Portugal and Iceland we find that the DSI has high levels, with values ranging between $49 \%$ for Italy and a staggering $167 \%$ for Portugal. This is caused by high volatility in growth and interest rates and a lack of fiscal response.

The fiscal response $(\rho)$ is instrumental in reducing the DSI. In particular for the last four countries in Table 2, the value of DSI drops when $\rho=7 \%$ is assumed. In other words, if these countries had a positive and significant fiscal response, their debts would have been more sustainable. Yet, even then, their fiscal position still does not reach the low levels of the other set of countries. In this respect, the historical volatility in real growth and interest rates is also crucial in explaining the expected large variability between countries, by indirectly measuring past macroeconomic volatility that creates greater expected uncertainty in the future.

To check whether DSI can be used as an early-warning indicator, we estimate using only data until 2007 and then run the simulations from 2007 to 2017 1ㅜㄹ Figure 5 plots DSI -based on data until 2007- against the average sovereign credit default swaps (CDS) rate between January 2009 and November 2012. We find a high correlation of 0.78 indicating a strong predictive power of our sustainability indicator. On the contrary, in 2007 there was hardly any variation in sovereign CDS spreads. Hence, the values of DSI in 2007 were, with the benefit of hindsight, more informative than the market based data on the fiscal stress that occurred after 2008. It

\footnotetext{
${ }^{40}$ The use of the $97.5 \%$ level is arbitrary, but using values of $95 \%$ and $99 \%$ yield the same qualitatively results.

${ }^{41}$ Similar results are find using as the starting year 2006 and 2005.
} 
Table 2: Summary of simulation outcomes and sustainability indicator for 2021

\begin{tabular}{lccccccc}
\hline & 2011 & & \multicolumn{2}{c}{$2021(\rho>0)$} & & \multicolumn{2}{c}{$2021(\rho=0)$} \\
\cline { 2 - 3 } \cline { 7 - 8 } \cline { 7 - 8 } & debt & & debt & DSI & & debt & DSI \\
United States & 102 & & 82 & 4 & & 95 & 6 \\
United Kingdom & 82 & & 73 & 9 & & 73 & 11 \\
Netherlands & 65 & & 50 & 8 & & 44 & 11 \\
Belgium & 99 & & 83 & 6 & & 85 & 7 \\
Germany & 80 & & 83 & 10 & & 92 & 12 \\
Italy & 120 & & 137 & 33 & & 182 & 49 \\
Spain & 68 & & 42 & 46 & & 56 & 58 \\
Portugal & 107 & & 132 & 132 & & 199 & 167 \\
Iceland & 99 & & 50 & 41 & & 78 & 55 \\
\hline
\end{tabular}

Notes: Units are percent of GDP. The Debt Sustainability Indicator (DSI) is defined in equation 7. The columns with $(\rho>0)$ use the $\rho$ values from Table 1 except for Spain, Portugal and Iceland for which we set $\rho=7 \%$. The columns with $(\rho=0)$ sets the $\rho$ values for all countries equal to zero.

clearly shows that Portugal, Iceland, Italy and Spain had high DSI values in 2007 that could predict the debt sustainability problems that occurred later on.

Figure 5: CDS rates in the crisis versus DSI prior to the crisis

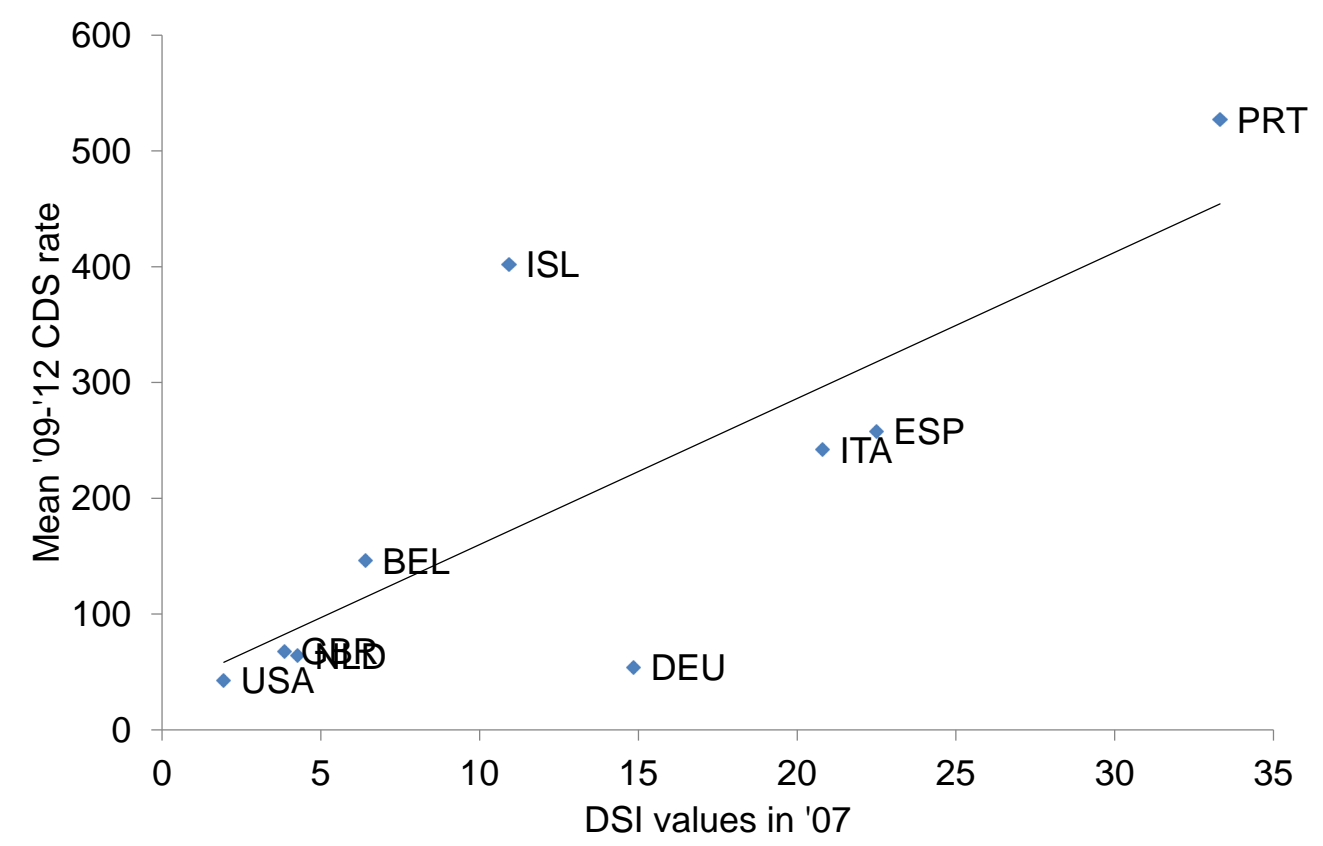

Source: Rates in basis points for 5 year Credit Default Swaps (CDS) from Datastream, observation window Jan-09 to Nov-12, indicators in percentages. 
While these results support using DSI as an early-warning instrument, a more rigorous assessment with a wider sample of countries that employs the signals approach of Kaminsky et al. (1998) should be undertaken ${ }^{42}$ Kaminsky et al. (1998) proposes, in the context of currency crisis, an early warning system based on the signal-to-noise ratio of an indicator for predicting a crisis 43

\section{Summary and conclusions}

We develop an indicator for debt sustainability which measures upward risk. It combines the effect of economic uncertainty -captured by stochastic simulations of interest and growth rates- with the expected response of the government budget to the debt level. We use long time series and find that five countries: the United States, United Kingdom, Netherlands, Belgium and Germany have persistently positive and significant fiscal reaction coefficients, conditional on temporary government spending (e.g. war expenditure) and cyclical economic fluctuations. These strong fiscal responses are found in both the full sample and also in the post-war period. In conjunction with on average moderate real growth and interest rates, their debt-toGDP ratios have been sustainable over time. Except for Germany, these countries emerged from the Second World War with high debt-to-GDP ratios. Until the midseventies, these debt levels were reduced drastically through low real interest rates. After the mid-seventies, real interest rates increased, while real growth rates were reduced and thus, these countries relied increasingly on fiscal responsibility (i.e. moderate primary surplus to GDP ratios) to keep debt at sustainable levels. The low values of our estimated DSI correctly reflect these facts.

On the other hand, for Spain, Portugal and Iceland, we do not find a significant fiscal response. Therefore, if real interest rates increase these countries are less prepared to maintain sustainable debt levels in the future. Our DSI clearly identifies this weakness in the debt dynamics of these countries by showing large upward risk. Finally, Italy has a positive and significant fiscal response coefficient, yet has debt sustainability concerns as its high current debt level makes it very susceptible to fluctuations in interest and growth rates. Therefore its debt sustainability indicator is large, which justifies the doubts on Italy's debt sustainability. As an aside, note that from a pure modelling point of view a better debt sustainability indicator for

\footnotetext{
${ }^{42}$ As a complement to this paper, we are currently expanding the country sample to include additional OECD countries and also emerging economies.

${ }^{43}$ This approach does not attempt to explain what drives the default probability, but merely tries to make a predictor that is as accurate as possible. Related papers include Berg et al. (2005) who perform a review of early-warning systems focusing primarily on the 1997 Asian crisis and report mixed results. Over the global financial crisis, Shi and Gao (2010) show the Kaminsky et al. (1998) early warning system did reasonably well during the crisis, albeit in a modified form. Several extensions to these type of indicators have recently been made. Dobrescu et al. (2011) extend the analysis to near-default events and show that including near-default events shows that fiscal stress remains high in advanced economies. Ciarlone and Trebeschi (2005) extend the two-state approach (default, non-default) to a three-state (default, non-default and post-default) and generate an early warning system which predicts $76 \%$ of entries into crisis, with $36 \%$ false alarms.
} 
Italy is more readily obtained by having a lower initial debt level and/or lower volatility in interest and growth rates than by increasing its fiscal response, which are similar to those in the United States, United Kingdom, Netherlands, Belgium and Germany, by strengthening fiscal institutions.

For medium to long-term fiscal policy assessments, indicators based on stochastic analysis and expected fiscal responses have several advantages over the currently available indicators at a medium term horizon. Both the momentary indicators (debt and deficit levels) and the ageing indicators (S1, S2) are static and do not capture volatility in the economy and the government's ability to control public finances. Alternative indicators currently in use, such as structural balances or cyclically adjusted budget balances (CABB), are often plagued by measurement issues. They depend on projections of future growth, which are known to have an upward bias (Larch and Salto, 2005), and their estimates are vulnerable to endogeneity problems: it is non-trivial to disentangle the effects of expected growth on the CABB from the effects the CABB has on expected growth. Our indicator do not suffer from these shortcomings, since it incorporates economic volatility and the government's expected policy response from ex-post realisations only.

Our analysis, however, has some caveats. First, our estimated fiscal response $(\rho)$ is an institutional variable that measures how - over medium and long-time periods the government of a particular country deals with medium/long term changes in debt levels. This means that we require long time series to estimate $\rho$, and furthermore, our approach is not suitable to analyse short-term debt sustainability. It cannot provide information on whether -for example- Spain will be able to roll over its debt in the coming months. Second, the shocks in our simulations depend on the historic volatility of interest and growth rates. That means they do not contain all possible unexpected exogenous events (e.g. war, natural disasters). The results of our simulation exercise are not informative on debt sustainability under such catastrophic conditions. Third, our indicator is not informative on the policy change that will solve the debt sustainability issue. Our framework merely states that countries with a higher and more significant historical fiscal policy response are more likely to solve such issues, should they arise. ${ }^{44}$

Therefore, our indicator is not meant to replace current indicators, but rather to complement the short term indicators and the indicators from ageing studies. They could, for instance, provide guidance on whether it is reasonable for a country to join a monetary union. In such a union, the use of financial and monetary policies is limited for individual countries, making it unlikely for them to achieve debt reductions through policies that yield very low or negative real interest rates. Thus, there is an increased dependence on fiscal policy to tackle debt sustainability. Our indicator captures this medium- to long-term institutional relation between fiscal policy and debt sustainability and complements it with the historical macroeconomic

\footnotetext{
${ }^{44}$ In contrast, ageing studies (European Commission, 2012a) analyse the impact of ageing on public finances given constant policy arrangements. If public finances are unsustainable, the policy arrangements most impacted by ageing should change until the problem is alleviated.
} 
stability of each country that is implicit in the volatility of real growth and interest rates.

Finally, we show that our indicator can be potentially useful as an early-warning indicator for debt sustainability, as it would have provided valuable information back in 2007 regarding the European sovereign debt crisis. Further tests, however, are still necessary to check the sensitivity of the DSI to different countries and samples, and to have a more robust assessment on how DSI performs as an early-warning debt sustainability indicator. 


\section{References}

Aaron, H. (1966). "The Social Insurance Paradox," Canadian Journal of Economics and Political Science, 32(3), 371-374.

Afonso, A. (2005). "Fiscal Sustainability: The Unpleasant European Case," FinanzArchiv, 61(1), 19-44.

Arezki, R., B. Candelon, and A. Sy (2011). "Sovereign Rating News and Financial Markets Spillovers: Evidence from the European Debt Crisis," IMF Working Paper 11/69.

Baffigi, A. (2011). "Italian National Accounts, 1861-2011," Economic History Working Papers 18, Banca d'Italia.

Bai, J. and P. Perron (1998). "Estimating and Testing Linear Models with Multiple Structural Changes," Econometrica, 66(1), 47-78.

Bai, J. and P. Perron (2003). "Computation and Analysis of Multiple Structural Change Models," Journal of Applied Econometrics, 18(1), 1-22.

Barro, R. J. (1979). "On the Determination of Public Debt," Journal of Political Economy, 87(5), 940-971.

Bartoletto, S., B. Chiarini, and E. Marzano (2013). "Is the Italian Public Debt Really Unsustainable? An Historical Comparison (1861-2010)," CESifo Working Paper Series 4185.

Baum, A., C. Checherita-Westphal, and P. Rother (2013). "Debt and Growth: New Evidence for the Euro Area," Journal of International Money and Finance, 32, 809-821.

Beetsma, R. and M. Giuliodori (2010). "The Macroeconomic Costs and Benefits of the EMU and Other Monetary Unions: An Overview of Recent Research," Journal of Economic Literature, 48(3), 603-641.

Berg, A., E. Borensztein, and C. Pattillo (2005). "Assessing Early Warning Systems: How Have They Worked in Practice?" IMF Staff Papers, 52(3), 462-502.

Berti, K. (2013). "Stochastic Public Debt Projections Using the Historical VarianceCovariance Matrix Approach for EU Countries," European Economy - Economic Papers 480, Directorate General Economic and Monetary Affairs (DG ECFIN), European Commission.

Berti, K., M. Salto, and M. Lequien (2012). "An Early-detection Index of Fiscal Stress for EU Countries," European Economy - Economic Papers 475, Directorate General Economic and Monetary Affairs (DG ECFIN), European Commission. 
Bohn, H. (1991). "Budget Balance Through Revenue or Spending Adjustments? Some Historical Evidence for the United States," Journal of Monetary Economics, $27(3), 333-359$.

Bohn, H. (1998). "The Behavior of U.S. Public Debt and Deficits," Quarterly Journal of Economics, 113(3), 949-963.

Bohn, H. (2007). "Are Stationary and Cointegration Restrictions Really Necessary for the IntertemporalBudget Constraing?" Journal of Monetary Economics, $54(7), 1837-1847$.

Bohn, H. (2008). "The Sustainability of Fiscal Policy in the United States," in Sustainability of Public Debt, ed. by R. Neck and J. Sturm, MIT Press, 15-49.

Bohn, H. (2011). "The Economic Consequences of Rising U.S. Government Debt: Privileges at Risk," FinanzArchiv: Public Finance Analysis, 67(3), 282-302.

Bos, F. (2007). "The Dutch Fiscal Framework: History, Current Practice and the Role of the CPB," CPB Discussion Paper, 150.

Brender, A. and A. Drazen (2005). "Political Budget Cycles in New Versus Established Democracies," Journal of Monetary Economics, 52(7), 1271-1295.

Brender, A. and A. Drazen (2008). "How Do Budget Deficits and Economic Growth Affect Reelection Prospects? Evidence from a Large Panel of Countries," American Economic Review, 98(5), 2203-20.

Budina, N. and S. van Wijnbergen (2008). "Quantitative Approaches to Fiscal Sustainability Analysis: A Case Study of Turkey since the Crisis of 2001," World Bank Economic Review, 23(1), 119-140.

Bursian, D., A. J. Weichenrieder, and J. Zimmer (2015). "Trust in Government and Fiscal Adjustments," International Tax and Public Finance, 22(4), 663-682.

Callen, T., M. Terrones, X. Debrun, J. Daniel, and C. Allard (2003). "Public Debt in Emerging Markets: Is it Too High?" in World Economic Outlook, International Monetary Fund, chap. III.

Catão, L. and S. Kapur (2006). "Volatility and the Debt-Intolerance Paradox," IMF Staff Papers, 53(2), 195-218.

CBS (1959). "Zestig jaren statistiek in tijdreeksen (1899-1959)," .

CBS (1994). "Vijfennegentig jaren statistiek in tijdreeksen (1899-1994)," .

CBS (2001). "Tweehonderd jaar statistiek in tijdreeksen (1800-1999)," .

Cecchetti, S., M. Mohanty, and F. Zampolli (2011). "The Real Effects of Debt," BIS Working Papers 352, Bank for International Settlements. 
Celasun, O., X. Debrun, and J. D. Ostry (2006). "Primary Surplus Behavior and Risks to Fiscal Sustainability in Emerging Market Countries: A "Fan-Chart" Approach," IMF Working Papers 06/67, International Monetary Fund.

Checherita-Westphal, C. and P. Rother (2012). "The Impact of High Government Debt on Economic Growth and its Channels: An Empirical Investigation for the Euro Area," European Economic Review, 56(7), 1392-1405.

Ciarlone, A. and G. Trebeschi (2005). "Designing an Early Warning System for Debt Crises," Emerging Markets Review, 6(4), 376-395.

Comín, F. and D. Díaz (2005). "Sector Público Administrativo y Estado del Bienestar," in Estadísticas Históricas de España: Siglos XIX y XX, ed. by A. Carreras and X. Tafunell, Bilbao, Spain: Fundación BBVA, 873-964, 2nd edition ed.

Dobrescu, G., I. Petrova, N. Belhocine, and E. Baldacci (2011). "Assessing Fiscal Stress," IMF Working Papers 11/100, International Monetary Fund.

Égert, B. (2012). "Public Debt, Economic Growth and Nonlinear Effects: Myth or Reality?" OECD Economics Department Working Papers 993, OECD Publishing.

European Commission (2012a). "Fiscal Sustainability Report 2012," European Economy 8/2012, Directorate-General for Economic and Financial Affairs, Brussels.

European Commission (2012b). "Report on Public Finances in the EMU," European Economy 4/2012, Directorate-General for Economic and Financial Affairs, Brussels.

Genberg, H. and A. Sulstarova (2008). "Macroeconomic Volatility, Debt Dynamics, and Sovereign Interest Rate Spreads," Journal of International Money and Finance, 27(1), 26-39.

Ghosh, A. R., J. I. Kim, E. G. Mendoza, J. D. Ostry, and M. S. Qureshi (2013). "Fiscal Fatigue, Fiscal Space and Debt Sustainability in Advanced Economies," The Economic Journal, 123(566), F4-F30.

Hall, R. E. (2013). "Fiscal Stability of High-Debt Nations under Volatile Economic Conditions," Working Paper 18797, National Bureau of Economic Research.

Höppner, F. and C. Kastrop (2004). "Fiscal Institutions and Sustainability of Public Debt in Germany," in Banca d'Italia Workshop on Public Debt, Perugia, Italia: Banca d'Italia, 575-594.

Kaminsky, G., S. Lizondo, and C. M. Reinhart (1998). "Leading Indicators of Currency Crises," IMF Staff Papers, 45(1), 1-48.

Krugman, P. R. (1988). "Financing vs. Forgiving a Debt Overhang," Journal of Development Economics, 29(3), 253-268. 
Larch, M. and M. Salto (2005). "Fiscal Rules, Inertia and Discretionary Fiscal Policy," Applied Economics, 37(10), 1135-1146.

Lejour, A., J. Lukkezen, and P. Veenendaal (2011). "Sustainability of Government Debt in the EMU," in The Economic Crisis and European Integration, ed. by W. Meeuwen, Cheltenham, UK: Edward Elgar, 35-54.

Maddison, A. (2003). The World Economy, Historical Statistics, Paris, France: OECD, Development Centre Studies.

Marinheiro, C. F. (2006). "The Sustainability of Portuguese Fiscal Policy from a Historical Perspective," Empirica, 33(2-3), 155-179.

Medeiros, J. (2012). "Stochastic Debt Simulation Using VAR Models and a Panel Fiscal Reaction Function - Results for a Selected Number of Countries," European Economy - Economic Papers 459, Directorate General Economic and Monetary Affairs (DG ECFIN), European Commission.

Mendoza, E. G. and J. D. Ostry (2008). "International Evidence on Fiscal Solvency: Is Fiscal Policy "Responsible"?" Journal of Monetary Economics, 55(6), 10811093.

Michell, B. R. (1988). British Historical Statistics, Cambridge, UK: Cambridge University Press.

OECD (2005). "Measuring Cyclically-adjusted Budget Balances for OECD Countries," OECD Working Paper, 434.

Peacock, A. T. and J. Wiseman (1961). The Growth of Public Expenditure in the United Kingdom, NBER Books, National Bureau of Economic Research.

Pirard, J. (1999). L'extension du rÃ'le de l'Etat en Belgique aux XIXe et XXe siècles, Brussels, Belgium.

Prados de la Escosura, L. (2003). El Progreso Económico de España (1850-2000), Bilbao, Spain: Fundación BBVA.

Reinhart, C. M. and K. S. Rogoff (2010). "Growth in a Time of Debt," Working Paper 15639, National Bureau of Economic Research.

Reinhart, C. M. and M. B. Sbrancia (2011). "The Liquidation of Government Debt," NBER Working Paper 16893, National Bureau for Economic Research.

Shi, J. and Y. Gao (2010). "A Study on KLR Financial Crisis Early-Warning Model," Frontiers of Economics in China, 5(2), 254-275.

van Zanden, J. L. (1996). "The Development of Government Finances in a Chaotic Period, 1807-1850," Economic and Social History in the Netherlands, 7, 53-71.

Wierts, P. and G. Schotten (2008). "De Nederlandse gasbaten en het begrotingsbeleid: Theorie versus praktijk," DNB Occasional Studies, 6(5). 


\section{A Standard unit root tests}

Table 3: Standard Advanced Dickey Fuller test results on the post WW2 sample.

\begin{tabular}{l|clll} 
& debt / GDP & ps / GDP & yvar & \multicolumn{1}{c}{ gvar } \\
\hline USA & -2.5 & $-4.7 * * *$ & $-6.1 * * *$ & $-6.0 * * *$ \\
GBR & -2.5 & $-7.7 * * *$ & $-5.5 * * *$ & $-12.0 * * *$ \\
NLD & -1.9 & $-5.1 * * *$ & $-2.8 *$ & $-3.8 * * *$ \\
BEL & -1.6 & -2.3 & $-4.0 * * *$ & $-5.1 * * *$ \\
DEU & 0.7 & $-3.0 * *$ & $-4.1 * * *$ & $-4.3 * * *$ \\
ITA & -0.3 & $-5.0 * * *$ & $-5.6 * * *$ & $-4.0 * * *$ \\
ESP & -1.3 & $-3.5 * * *$ & $-4.2 * * *$ & $-5.8 * * *$ \\
PRT & 1.1 & -2.4 & $-5.8 * * *$ & $-4.4 * * *$ \\
ISL & 0.2 & $-3.3 * *$ & $-3.7 * * *$ & $-3.4 * *$
\end{tabular}

Significance levels: $* * * \mathrm{p}<0.01,{ }^{* *} \mathrm{p}<0.05,{ }^{*} \mathrm{p}<0.1$

Table 4: Cholesky decomposed residuals matrix.

\begin{tabular}{lrrr}
\hline & int,int & int,gr & gr,gr \\
\hline USA & 0.43 & 1.06 & 1.14 \\
GBR & 0.38 & 0.31 & 1.77 \\
NLD & 0.31 & 1.44 & 1.76 \\
BEL & 0.56 & -0.29 & 1.62 \\
DEU & 0.38 & 1.03 & 1.71 \\
ITA & 0.39 & 0.71 & 1.46 \\
ESP & 4.83 & -0.26 & 2.04 \\
PRT & 0.69 & 0.67 & 2.17 \\
ISL & 1.96 & 0.23 & 3.96 \\
\hline
\end{tabular}

Values x100

\section{B Regression results}




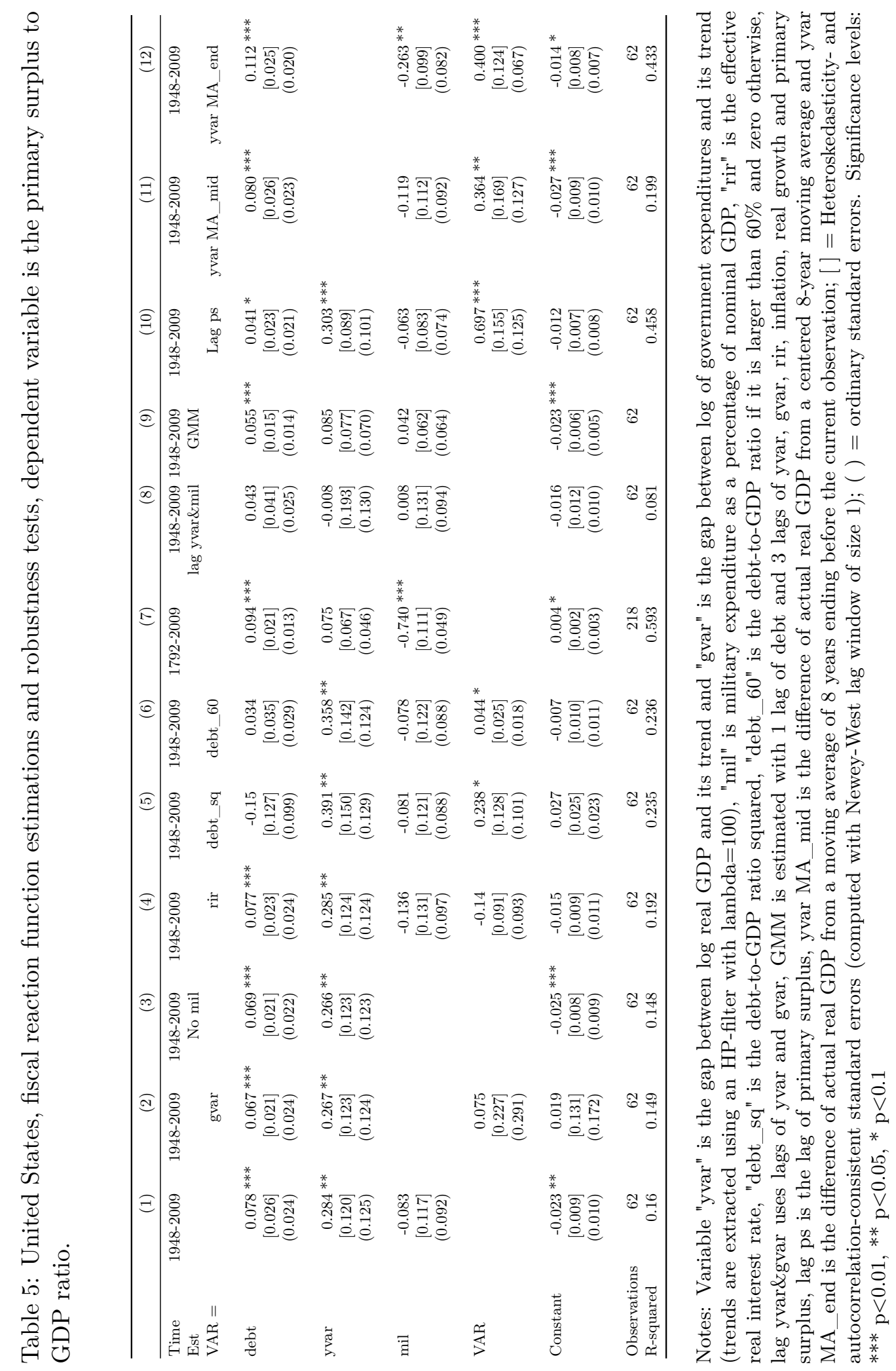




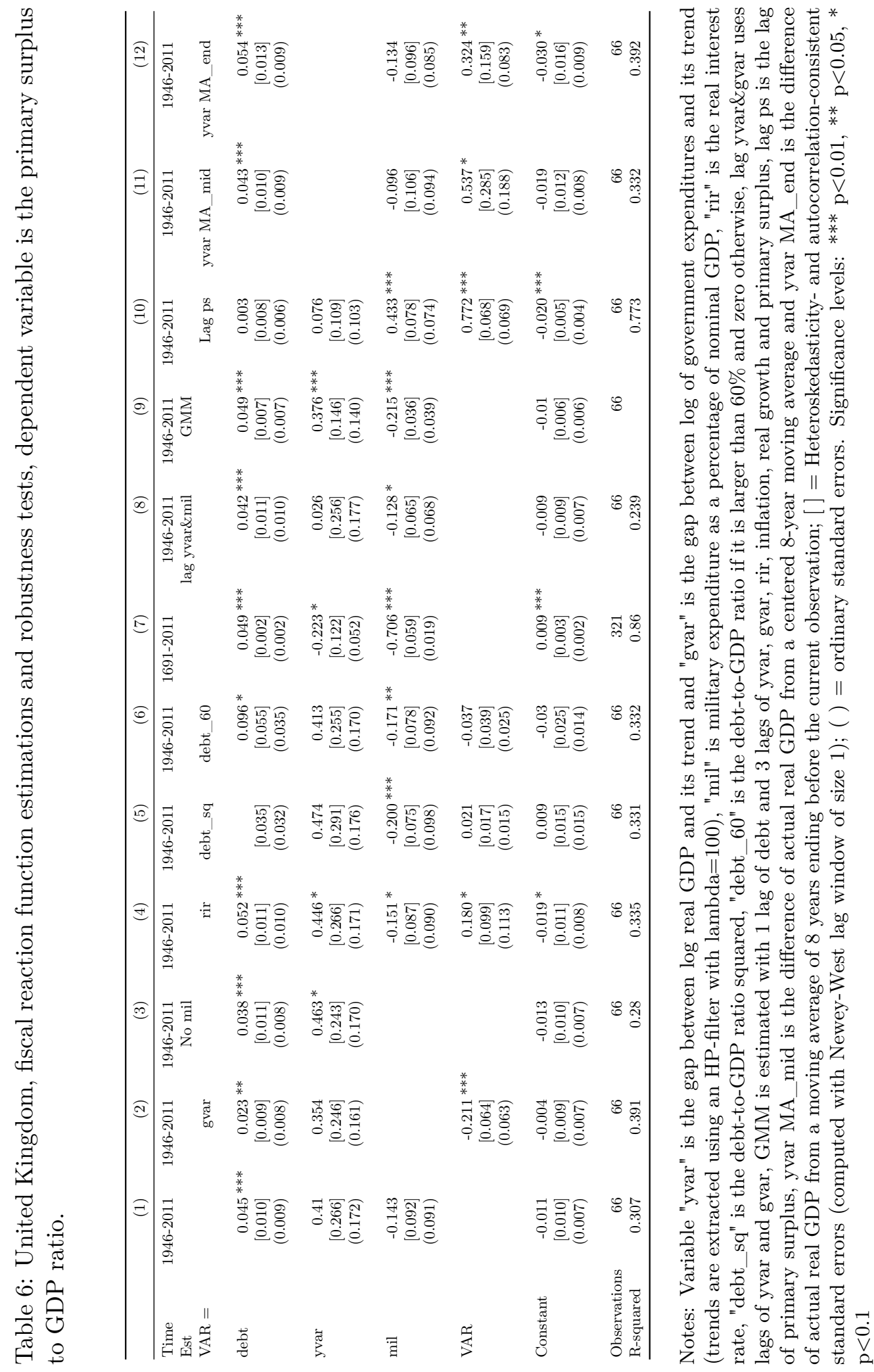




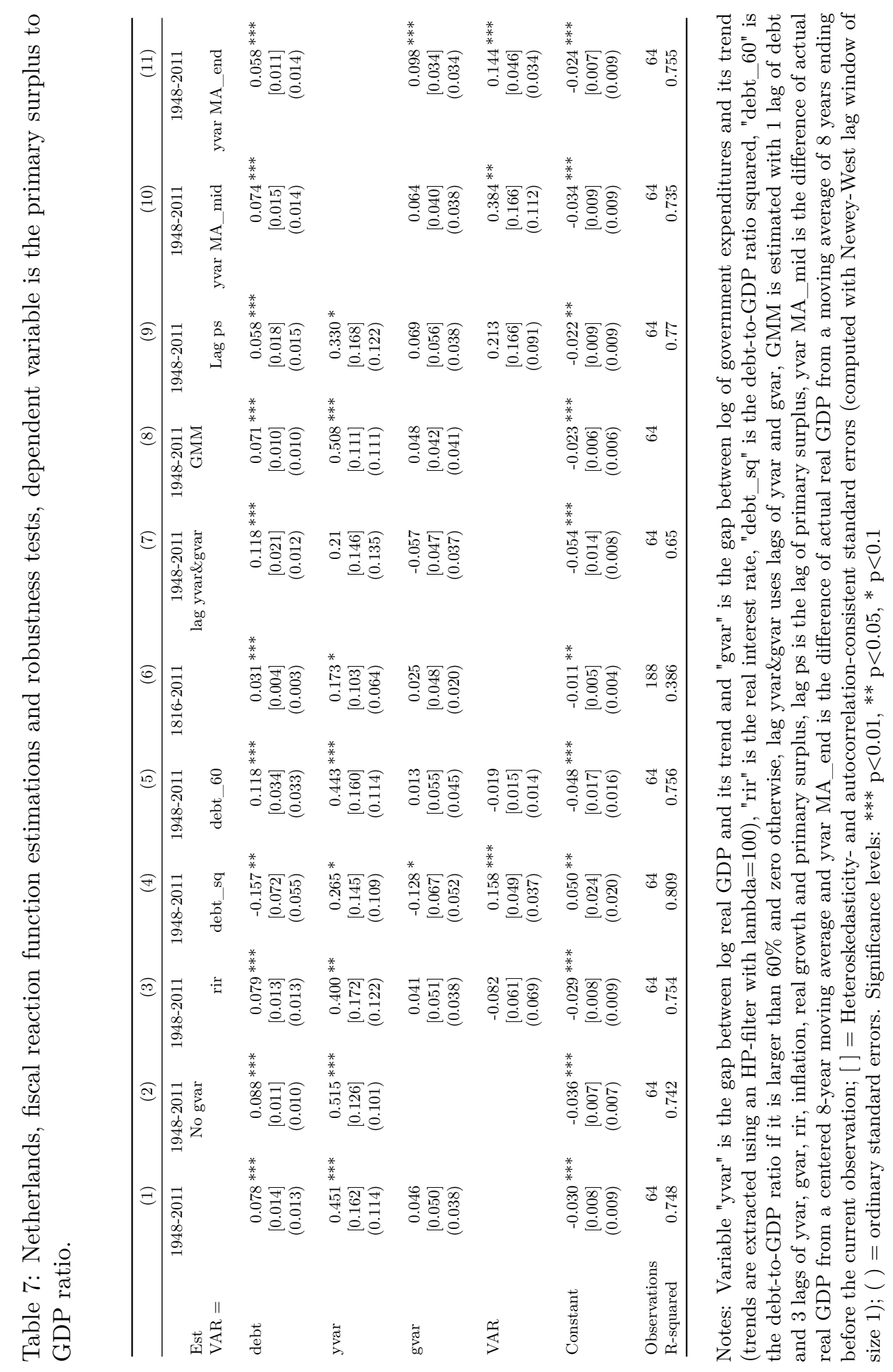




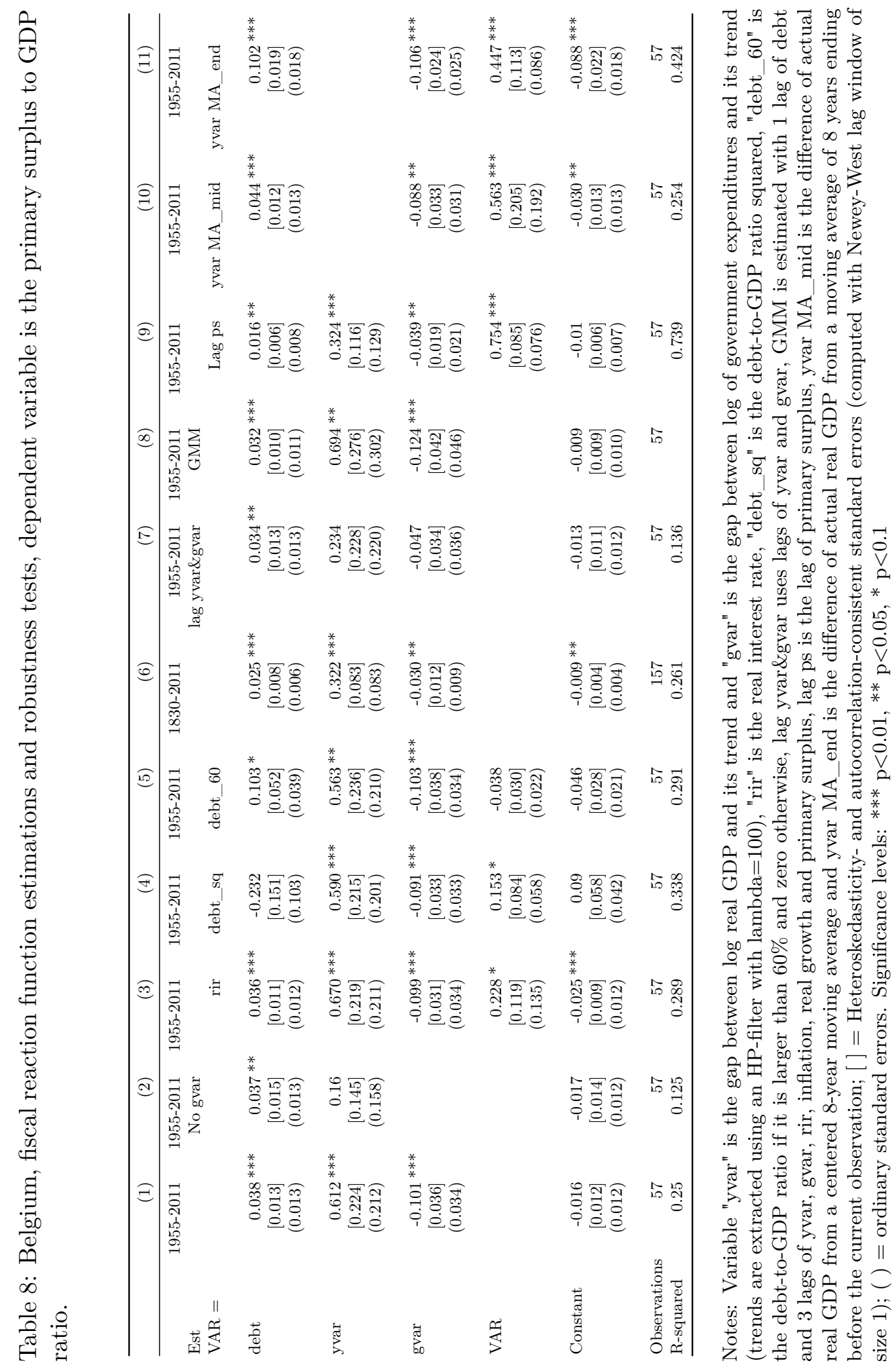




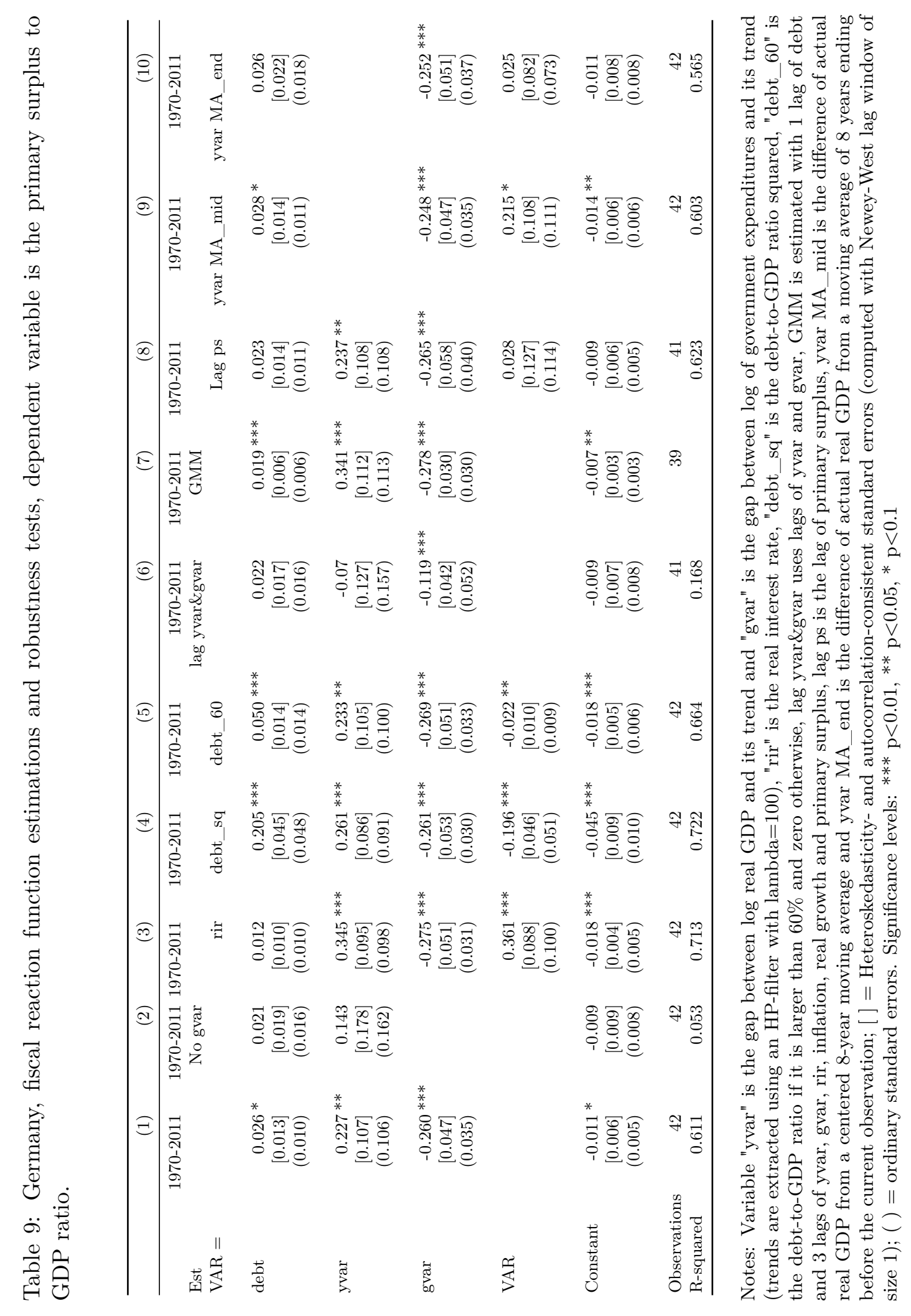




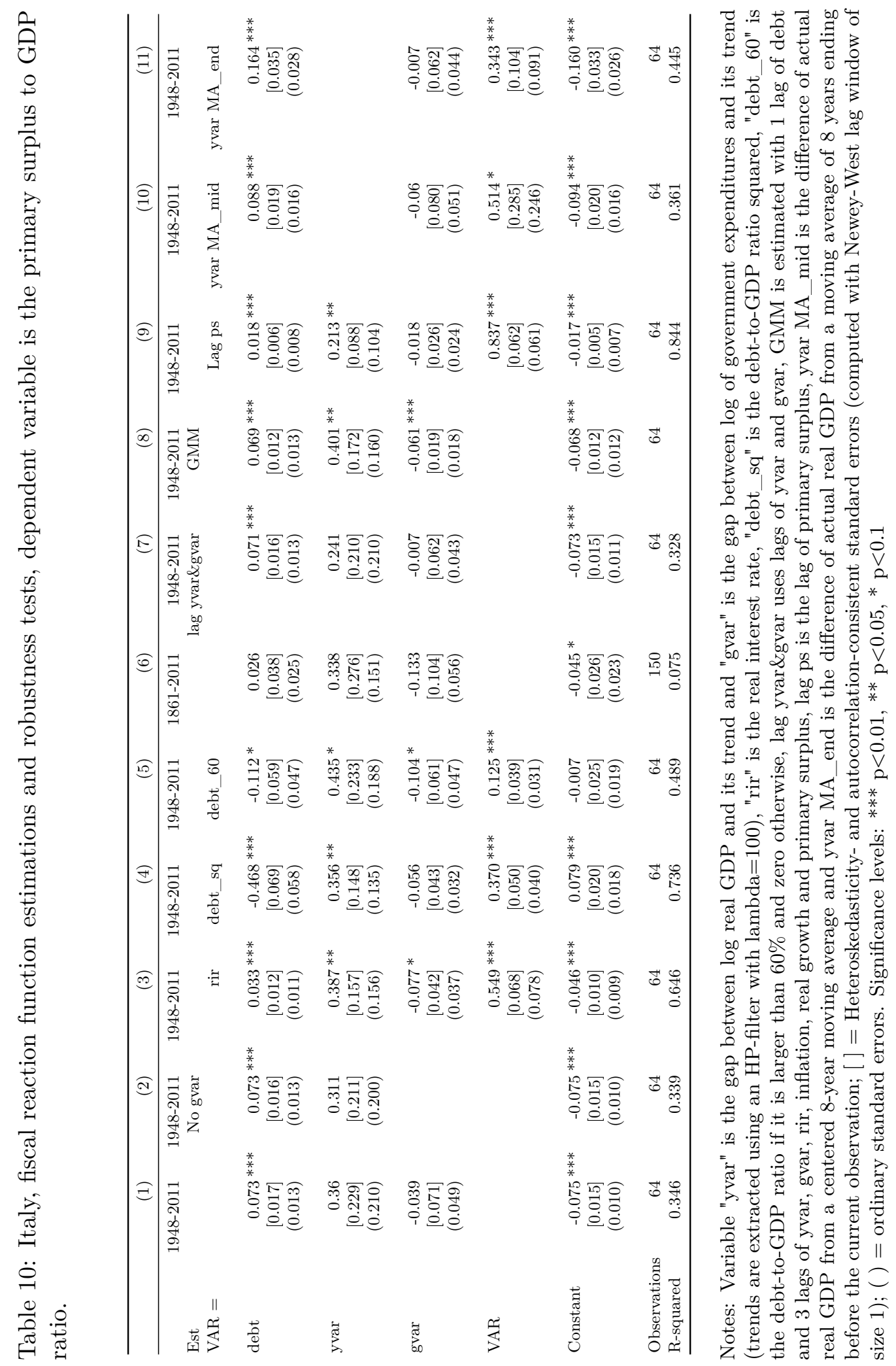




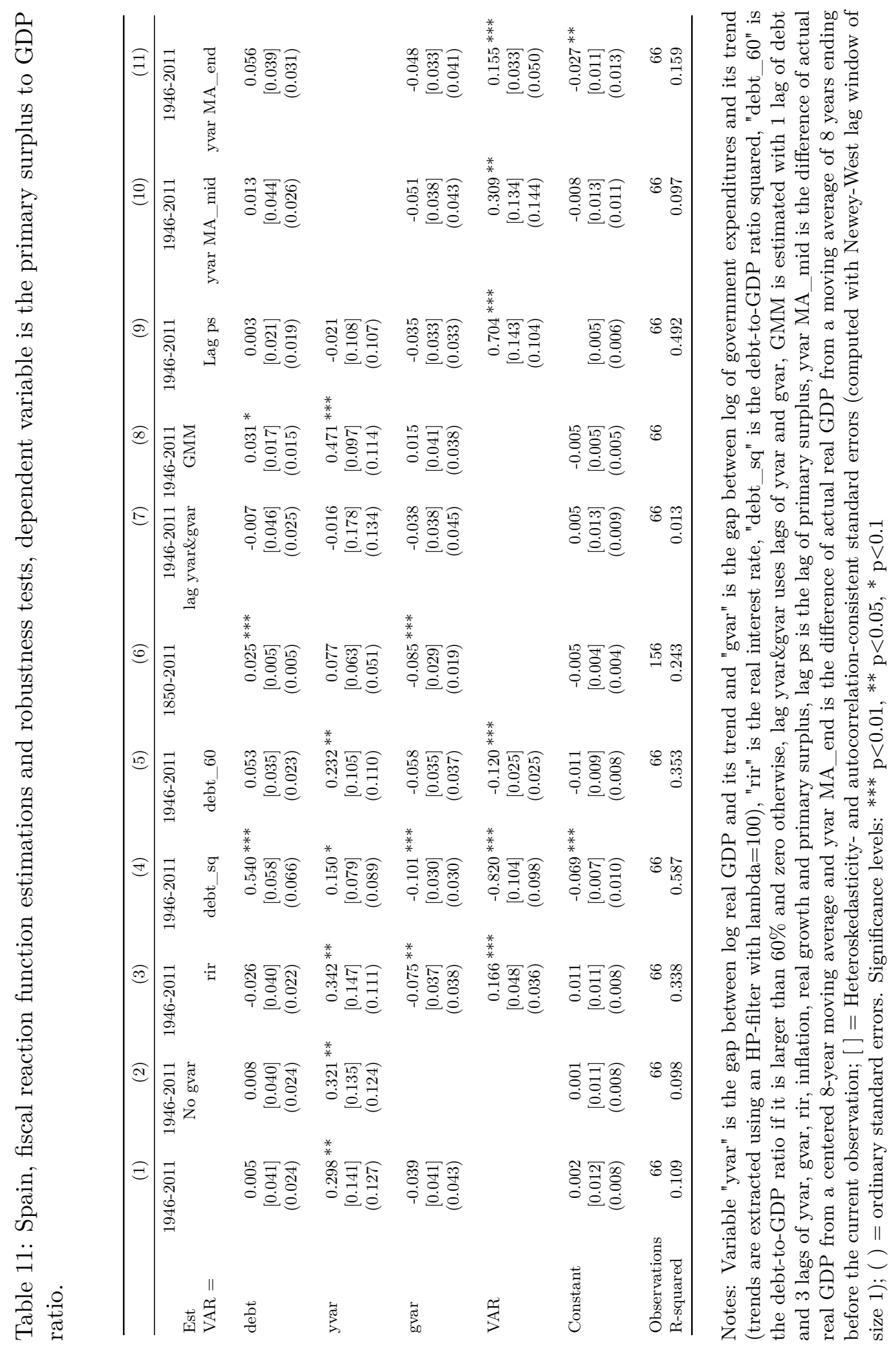




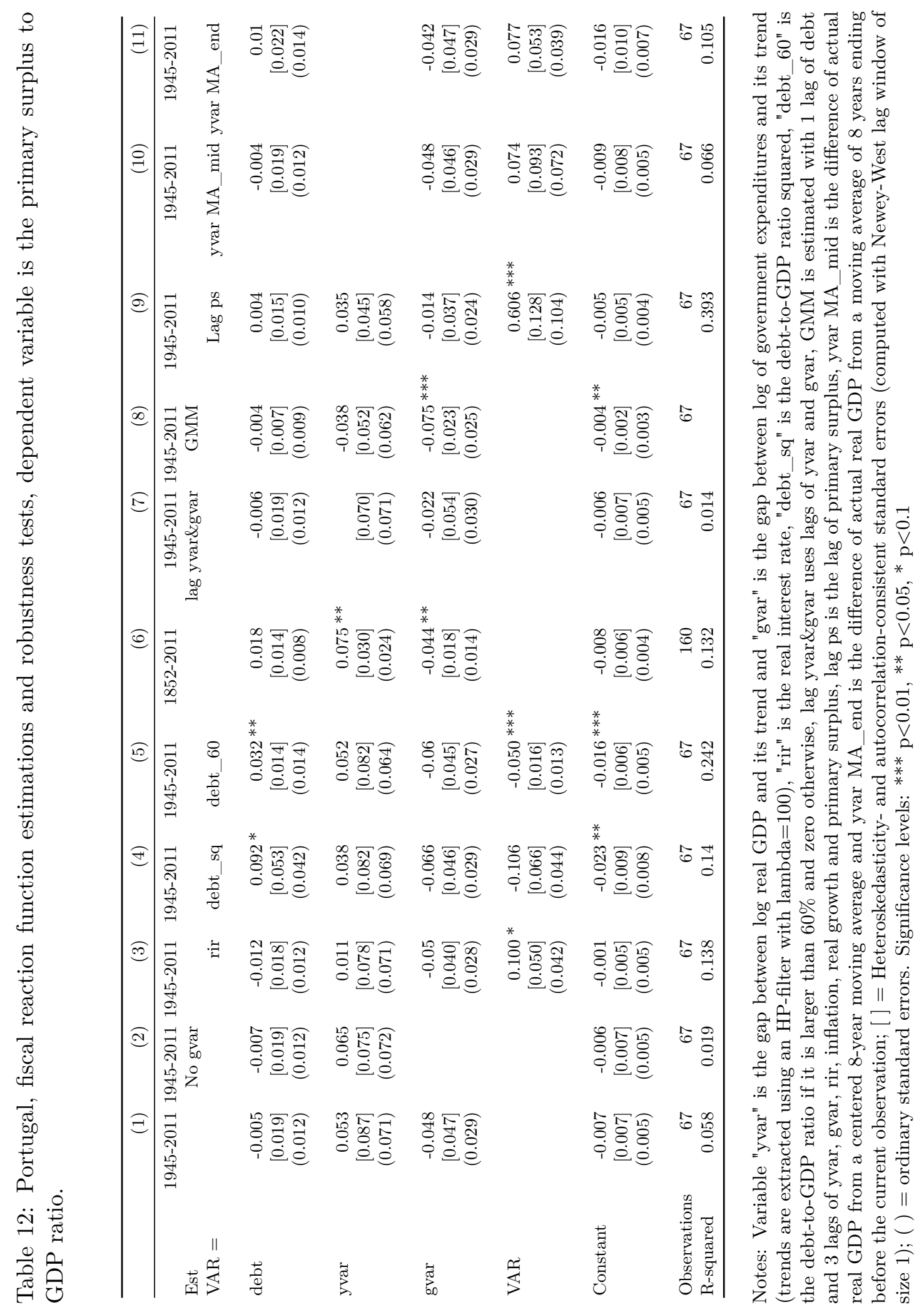




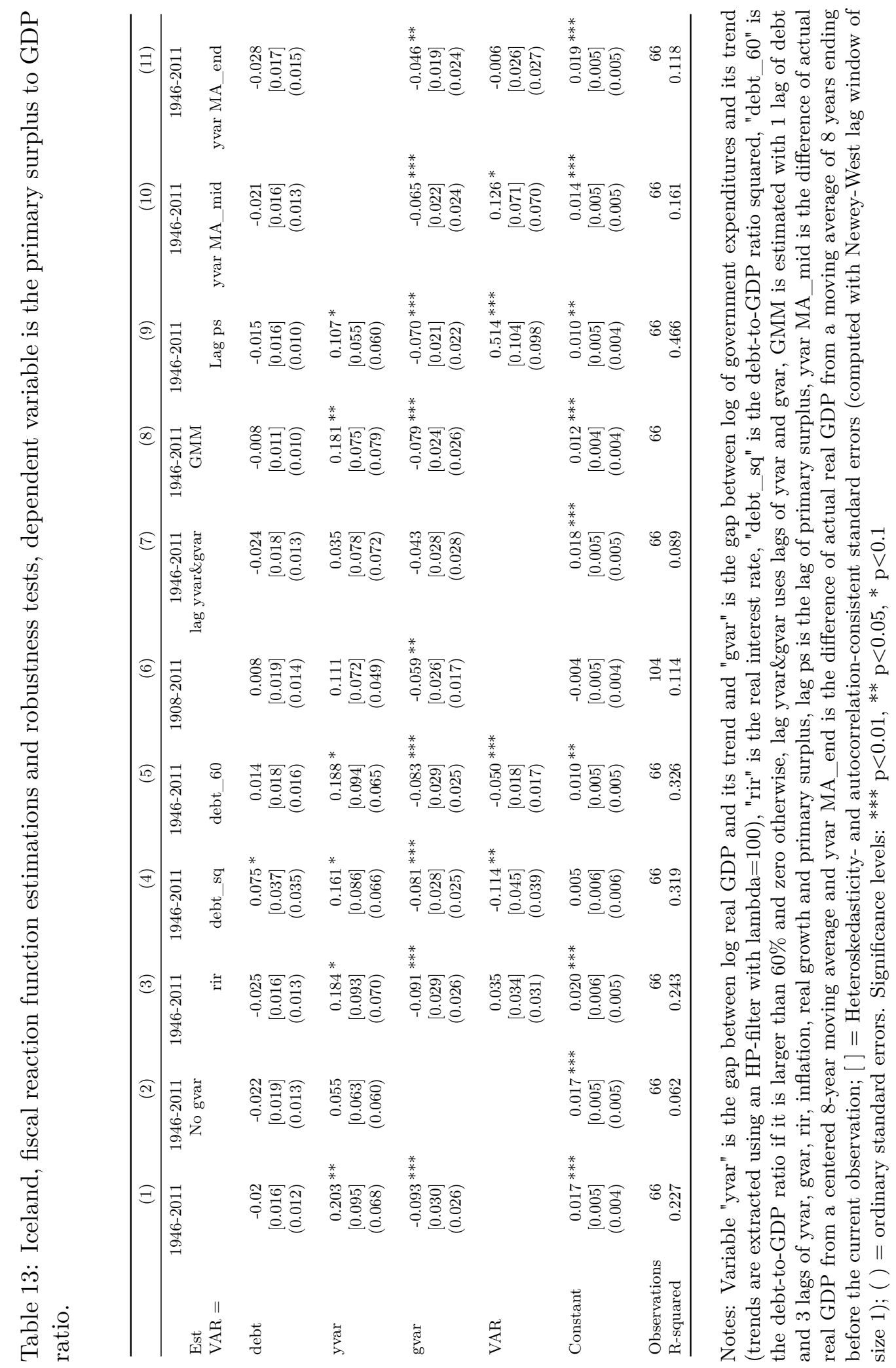




\section{Data sources and country graphs}

Under the subsequent country headings we describe our data sources, elaborate on the definitions used (general/central government) and whether breaks in the data are present. Table 14 presents a summary of the available data for each country.

Table 14: Available data per country

\begin{tabular}{lcccc}
\hline Country & & Samples & Observations \\
USA & $1792-2011$ & & 218 \\
United Kingdom & $1691-2011$ & & & 321 \\
Netherlands & $1816-1939$ & $1948-2011$ & & 188 \\
Belgium & $1830-1913$ & $1919-1939$ & $1955-2011$ & 157 \\
Germany & $1970-2011$ & & & 42 \\
Italy & $1861-2011$ & & & 150 \\
Spain & $1850-1935$ & $1940-2011$ & 156 \\
Portugal & $1852-2011$ & & 160 \\
Iceland & $1908-2011$ & & 104 \\
\hline
\end{tabular}

In Figures 8,12 we plot the debt-to-GDP ratio, the primary surplus to GDP ratio, a smoothed series of interest minus growth rate and for the United Kingdom and the US the GVAR indicator.

As the effective interest rate we use the simple formula: $i_{t}^{e}=i p_{t} / d_{t-1}$ where $i^{e}$ is the effective interest rate and $i p$ is interest payment on debt $d$, both in nominal terms 45

\section{United States}

We use the data from Bohn (2008) from 1792-2009 46 We updated this data until 2011. This is a continuous dataset on nominal and real GDP, government gross debt, government primary surplus, government interest expenditure and government military expenditure. A detailed description of the data used there can be found in Bohn (1991) and Bohn (2008), and references therein.

Note that the data by Bohn provides gross federal debt levels for the United States that are in the hands of the public. It does not include other governmental holdings of federal debt. In our analysis we assume the gross federal debt not in hands of the public remains constant as a share of GDP.

Government military expenditure is used as an indicator for temporary government spending GVAR as government expenditure in wartime is significantly different

\footnotetext{
${ }^{45}$ This simple formula is almost perfectly correlated (0.9975) with a more precise specification given by: $i_{t}^{e}=\frac{i p_{t}}{2}\left(\frac{d_{t}}{\sqrt{\pi_{t}}}+\frac{d_{t-1}}{\sqrt{\pi_{t}}}\right)^{-1}$ where $p$ is the GDP deflator and $\pi_{t}=p_{t} / P_{t-1}$.

${ }^{46}$ Henning Bohn kindly provided us with an updated database which runs until 2009. He used the 2011 Budget of the United States for this update.
} 
from government spending in peacetime. Using dummy variables for the war years ${ }^{47}$ instead of actual military expenditure does not change the results significantly.

\section{United Kingdom}

The sample from the United Kingdom is from 1692-2011 with a break in 1800 and in 1946. There is a shift in the reporting year in 1800, prior to 1946 we use central government data and after 1946 we use general government data. We use military expenditure as a proxy for temporary government spending and there is a break in this series in 1980 probably due to a different specification. Prior to 1946 military expenditure and interest expenditure are the only two large items on the central governments budget. Non-military non-interest spending never exceeds $2 \%$ of GDP.48 Data is obtained from six sources:

- Data on central government expenditure (1692-1945), interest expenditure (1692-1945), military expenditure (1692-1980), revenue (1692-1946), public debt (1692-1979), CPI as a proxy for the GDP deflator (1691-1792), a GDP deflator (1830-1946) and nominal GDP (1830-1946) has been obtained from Michell (1988).

- From Peacock and Wiseman (1961) real and nominal GDP is obtained for the years 1792, 1800, 1814, 1822, 1831. Constant growth rates in real and nominal GDP are assumed between these dates.

- Real GDP for 1700 and 1800 is obtained from Maddison (2003) world historic tables. Constant growth rates in real GDP is assumed between 1700 and 1792 and in the period 1691-1700.

- General government expenditure, interest expenditure, revenue and real and nominal GDP from 1946 onwards is obtained from the Office of National Statistics

- Public debt is obtained from the United Kingdom Ministry of Finance for 1980-2011

- Military expenditure for 1980-2011 is obtained from the OECD.

A GDP deflator and real GDP from 1692-2011 is obtained by coupling the various partial GDP series with each other. Furthermore GDP has been adjusted such that Ireland is excluded prior to 1920 as it is after 1920. Temporary government expenditure GVAR is military spending. As an alternative we use gap between the $\log$ of government expenditure and its trend.

\footnotetext{
${ }^{47}$ 1812-1815 War of 1812, 1846-1849 (Mexican-American War), 1861-1865 (American Civil War), 1917-1920 (World War I), 1940-1945 (World War II)

${ }^{48}$ Except for 1836 and 1837. In these years the government compensated slave owners for outlawing slavery.
} 


\section{Netherlands}

Data is obtained from Bos (2007) and contains nominal GDP, a piecewise continuous GDP deflator, gross government debt and a decomposition of government revenue and government expenditure in their main components. It runs from 1815 till 2009 with gaps in the inter-war years. Bos (2007)acquires data on general government finances in the period 1815-1900 from the work of van Zanden (1996) and from 1900 onwards from Statistics Netherlands. In the period 1850-1900 only data on central government finances are available. Furthermore data on local government interest expenditure is missing until 1947.

We correct for that by using two assumptions. First, we assume that the interest rate on non-central government debt equals the interest rate on central government debt. In the Netherlands, the central government steps in and assumes full liability when local governments are in financial distress. Therefore local government default risk is equal to central government default risk. Second we assume that local government finances have run a balanced budget, as they are required by law, and we interpolate non-central government debt between 1850 and 1900 linearly. This seems a reasonable first assumption as in 1850 non-central government debt is $26.0 \%$ of general government debt, in 1900 it is $20.2 \%$. If these assumptions underestimate local interest expenditure, primary surplus and implied interest rates prior to 1947 would be lower than their actual value. The effect on debt sustainability will be absent, as primary surplus and the implied interest rates have opposite signs in the accounting equation. This has been tested by using central instead of general government finances. As none of the regression coefficients except for the constant to changed by more than one standard deviation, we deem these assumptions reasonable.

Bos (2007) provides GDP deflators from 1815-1913, 1921-1939 and 1948-2009, Statistics Netherlands (CBS, 1959, 1994, 2001) provides a consumer price index from 1900-2009. A continuous GDP deflator is constructed by using consumer price indices to bridge the gap between the broken piece-wise continuous GDP deflators. We approximate the GDP deflator from 1913-1921 and from 1939-1948 by the consumer price index. The consumer price index is highly correlated with the GDP deflator in the period 1900-1913, 1922-1939 and 1949-2009: correlation is 0.998 on level and 0.949 on first differences.

Temporary government expenditure is defined as the residual of government expenditure after its HP-filtered mean has been removed. Note that Bohn (2008) uses military expenditure as an alternative measure of temporary government expenditure. Unlike the United States, where military spending drives government spending prior to 1948, the only notable Dutch event is the Belgian war of independence in 1830. Wierts and Schotten (2008) argue gas revenue should be used from 1970s onwards as it had considerable impact in budgetary policy. Both alternative specifications are used in robustness checks and do not provide significant changes. 


\section{Belgium}

The sample from Belgium is from 1830-1913, 1920-1939 and 1955-2011 with a break in 1970. Prior to 1970 central government data is used, after 1970 general government data. Data for Belgium has been obtained from 4 sources:

- A dataset on Belgium's central government finances from the independence of the state in 1830 until the first world war (1913) was created by Joseph Pirard and published in Pirard (1999). He reports central government revenue, expenditure, gross government debt, interest expenditure nominal GDP from 1830 onwards. In this book Pirard also publishes this data for the Inter bellum (1920-1939) and the years after the Second World War (1945-1995), which he obtains from other sources. finance data after 1945 as the increase in debt is always smaller than the difference between government revenue and government expenditure and much to persistent to be due to stock-flow adjustments. This might be due to the fact that some government bond redemptions are classified as government expenditure.

- Real GDP for the period 1830-1960 is obtained from Maddison (2003) world historic tables. For the years 1831-1839 no data is available here and thus a constant increase between 1830 and 1840 is assumed.

- Data on central government finances (revenue from 1955 until 1970 is obtained from the annual reports of the $\mathrm{NBB}$, the Belgian central bank.

- From 1970 onwards data on general government finances and GDP is available from the AMECO database of the European Commission.

The nominal GDP estimates of Pirard are in the period 1970-1995 approximately $13 \%$ lower than the AMECO data. We correct for this by increasing every data-point in the nominal GDP series of Pirard by $13 \%$. Temporary government expenditure GVAR is determined as the gap between the log of government expenditure and its trend.

\section{Germany}

We use the data from Höppner and Kastrop (2004), which was updated for 2011 by Elke Baumann. The have GDP and debt series starting in 1960, but only fiscal data starting from 1970. From 1980 to 2011 we use the IMF World Economic Outlook (April 2012) data on General Government expenditure, revenue, and budgetary surplus.

\section{Italy}

We use the data from Bartoletto et al. (2013) from 1861-2009 for consolidated debt of the General Government, total expenditure and interest payments. This is complemented with data from Baffigi (2011) for time series on nominal and real GDP. 
Furthermore, we update these data until 2011 using the IMF World Economic Outlook (April 2012) to obtain data on real and nominal GDP, General Government gross debt, expenditure, revenue and primary surplus.

Since there was no data in Bartoletto et al. (2013) on governmental revenue, the budgetary surplus was estimated using the difference in gross debt with respect to its previous year. From 1988 onwards we substitute the historical data with the IMF WEO data on primary surplus. The correlation between both primary surplus sources is 0.86 and our econometric results are qualitatively the same.

\section{Spain}

The sample is from 1850 to 2011 with a gap for the Spanish Civil War (1936-1939). Data prior to 1995 is taken from Prados de la Escosura (2003) for GDP data in real and nominal terms and Comín and Díaz (2005) for the public sector data and concerns national and provincial government finances. After 1995 data is obtained from the AMECO database of the European Commission.

Temporary government expenditure GVAR is determined as the gap between the log of government expenditure and its trend.

\section{Portugal}

The sample is from 1850 to 2011. Data comes from Marinheiro (2006) for the period 1852-1995. In the statistical appendix to that paper Marinheiro describes the sources from which he obtains his data. This is a continuous dataset on nominal and real GDP, government gross debt, government primary surplus and government interest expenditure. The government finances are on cash basis. After 1995 data is obtained from the AMECO database of the European Commission.

Marinheiro (2006) also constructed interest rates for Portugal which are about three percentage points higher on average than the ones estimated using actual interest payments. However, our results did not change qualitatively using this alternative.

Temporary government expenditure GVAR is determined as the gap between the $\log$ of government expenditure and its trend. Portugal defaulted on its government debt in 1892, which was ultimately resolved in 1902.

\section{Iceland}

The sample for Iceland is from 1908-2011. Data for Iceland has been obtained from two sources. A since 2000 defunct Icelandic organisation 'Pjóðhagsstofnun' published general government revenue, expenditure, gross government debt, interest expenditure and real and nominal GDP from 1908 until 1999. Iceland statistics publishes data on general government revenue, expenditure, gross government debt, interest expenditure and real and nominal GDP from 1945 onwards. The data between 1945 and 1999 is identical to the data on the "Pjóðhagsstofnun" website. 
Icelandic data concerns general government and contains long periods of high inflation. Temporary government expenditure GVAR is determined as the gap between the log of government expenditure and its trend. Iceland sought and received assistance from the IMF and the Scandinavian countries after the 2008 banking crisis turned into a sovereign debt crisis for Iceland. This is considered as a public debt default. 
Figure 6: Real growth rates (smoothed series) in the post-war period.
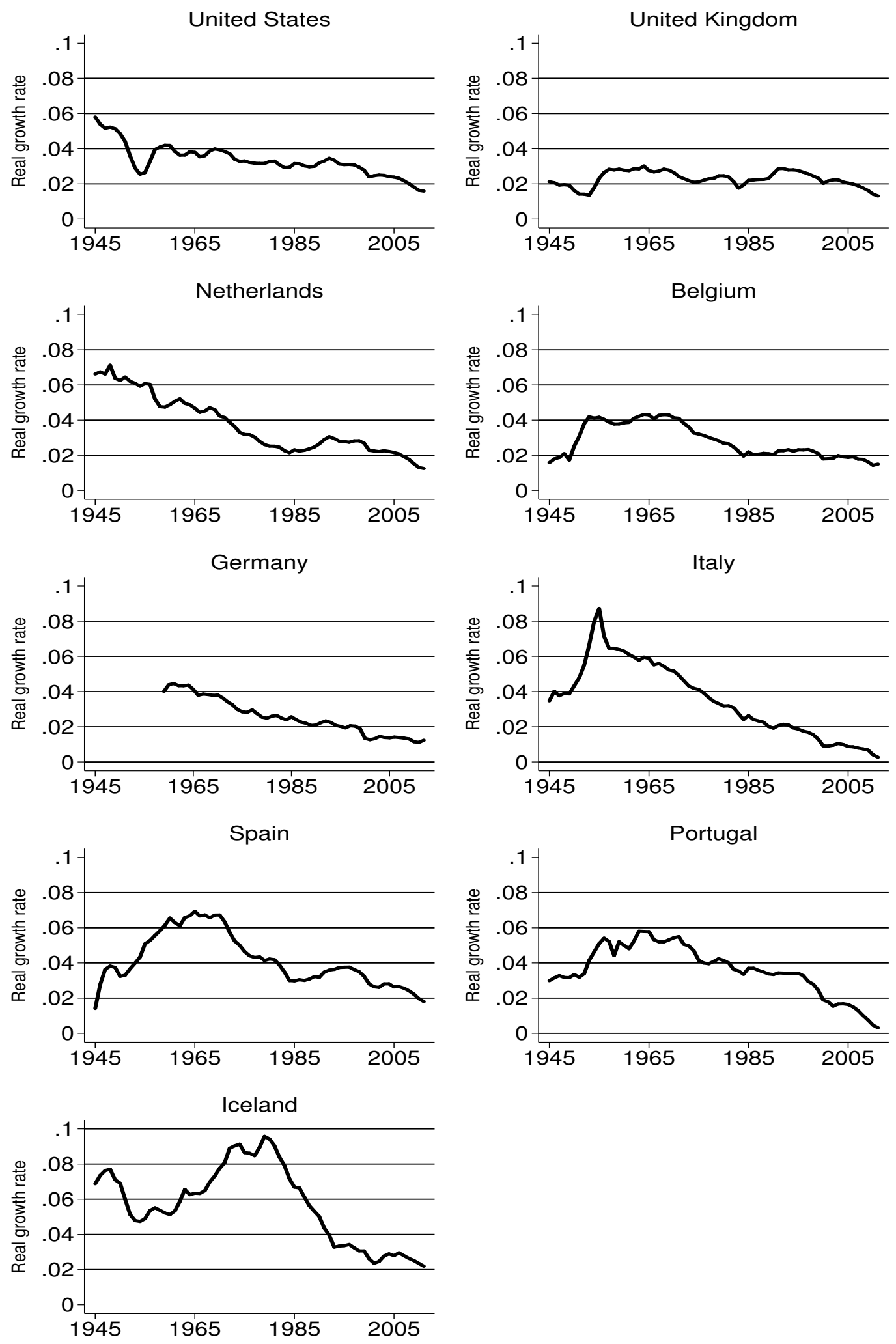
Figure 7: Nominal interest rates (straight line) and inflation (dotted line) in the post-war period (the vertical scale can be different across countries).
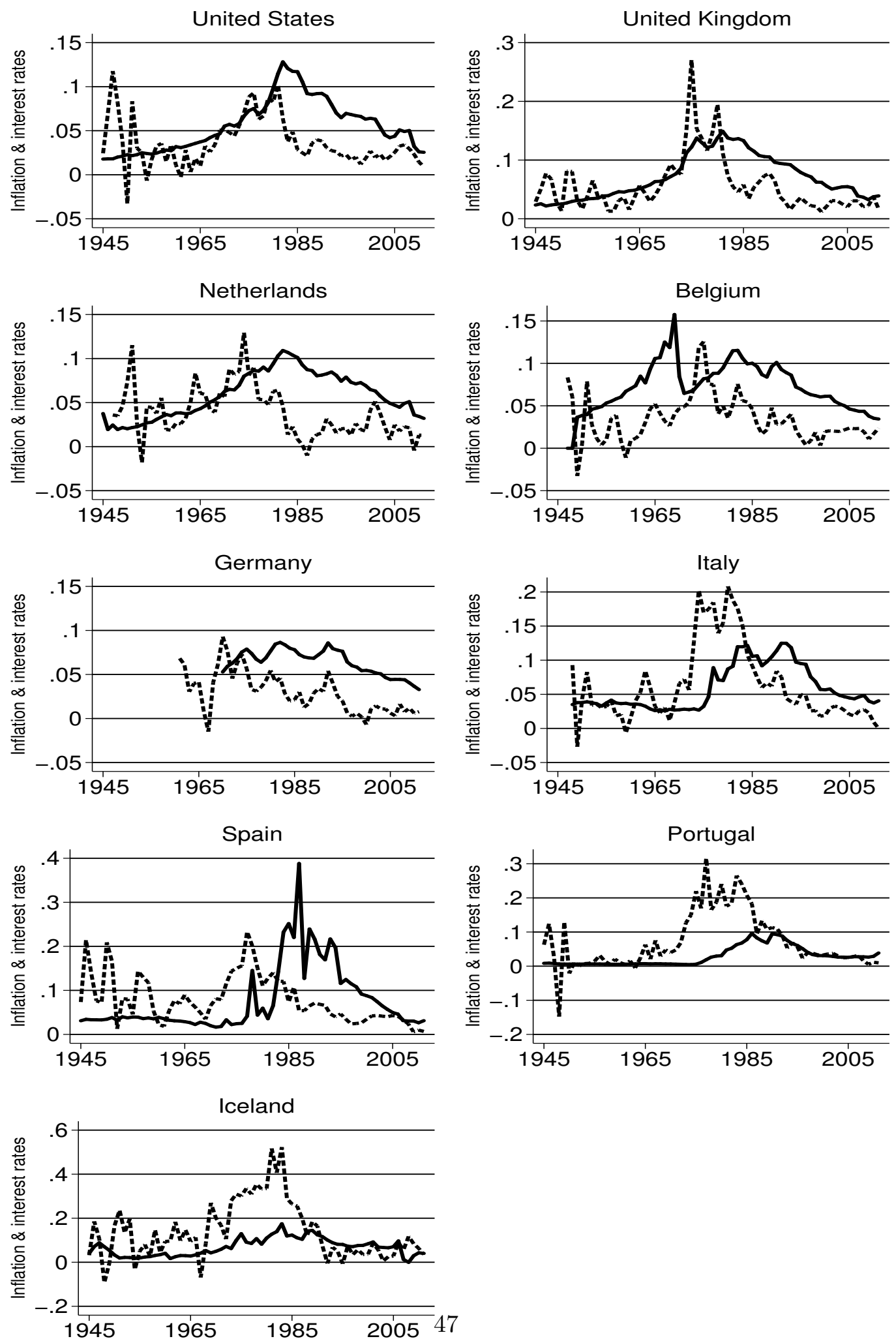
Figure 8: United States and United Kingdom: Debt, primary surplus and military expenditure ratios to GDP, and gamma parameter, post-war samples
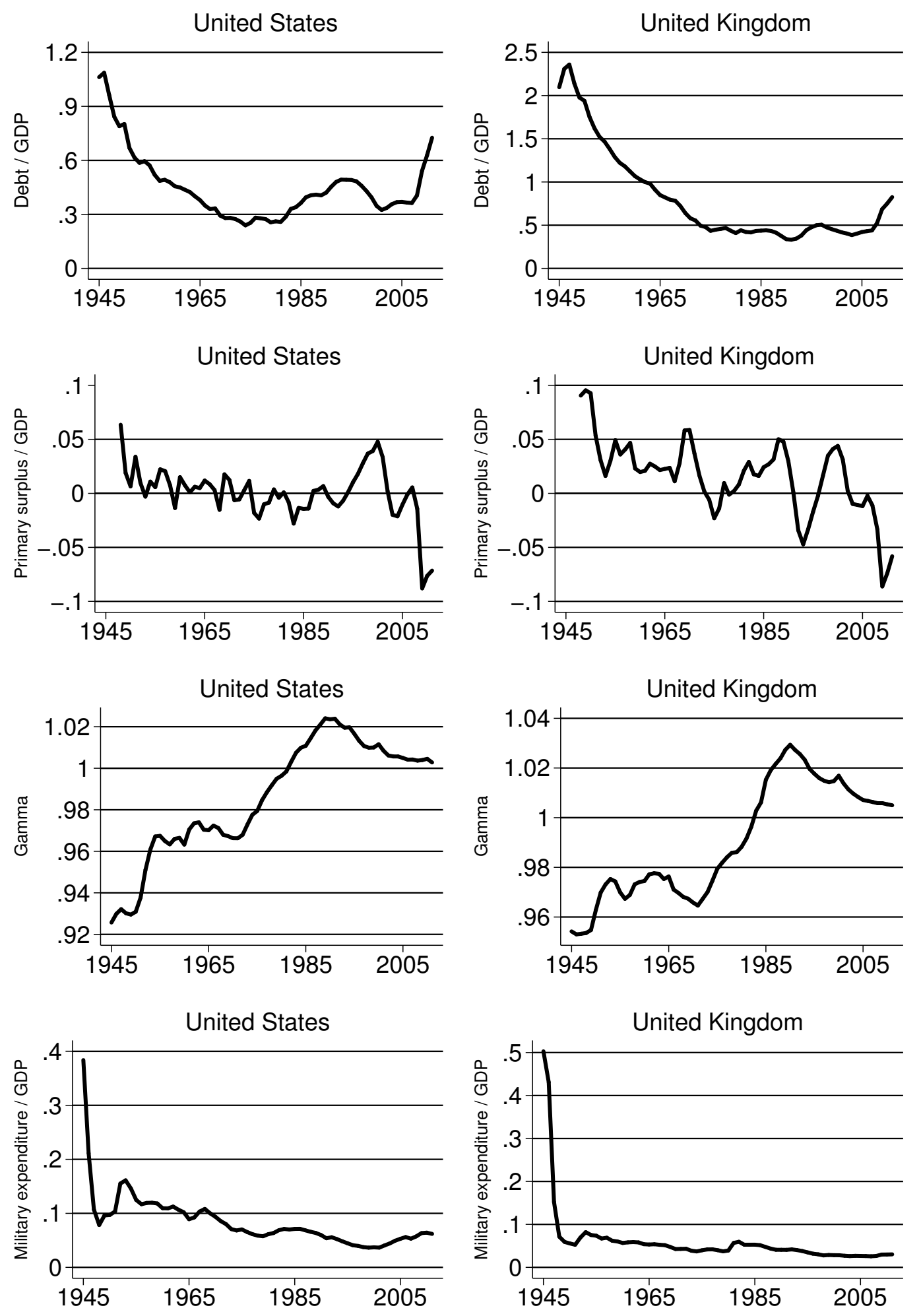

Notes: Gamma is one plus the smoothed series of the effective interest rates minus the smoothed series of nominal GDP growth rates. 
Figure 9: Netherlands and Belgium: Debt and primary surplus ratios to GDP, and gamma parameter, post-war samples
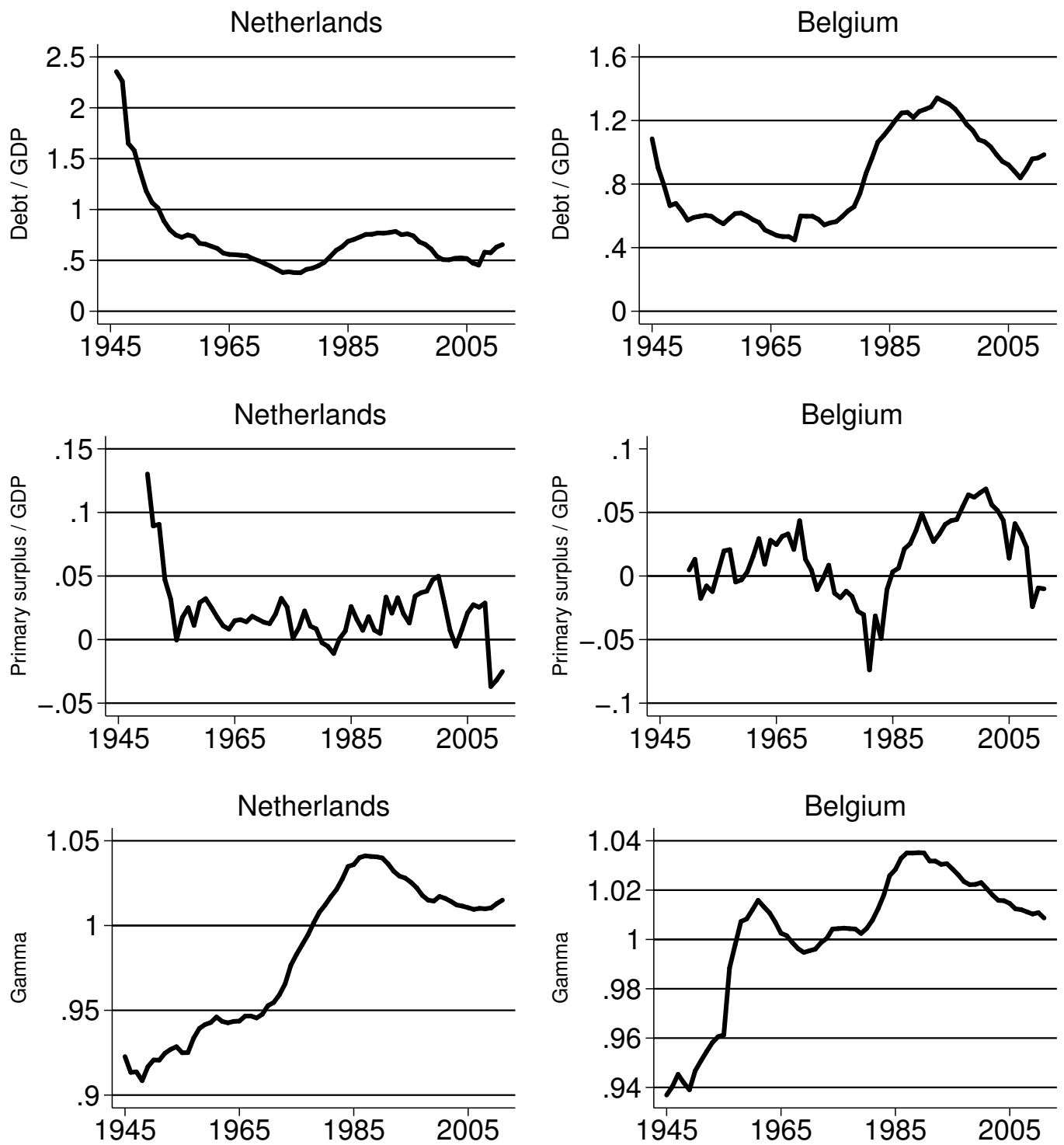

Notes: Gamma is one plus the smoothed series of the effective interest rates minus the smoothed series of nominal GDP growth rates. 
Figure 10: Germany and Italy: Debt and primary surplus ratios to GDP, and gamma parameter, post-war samples
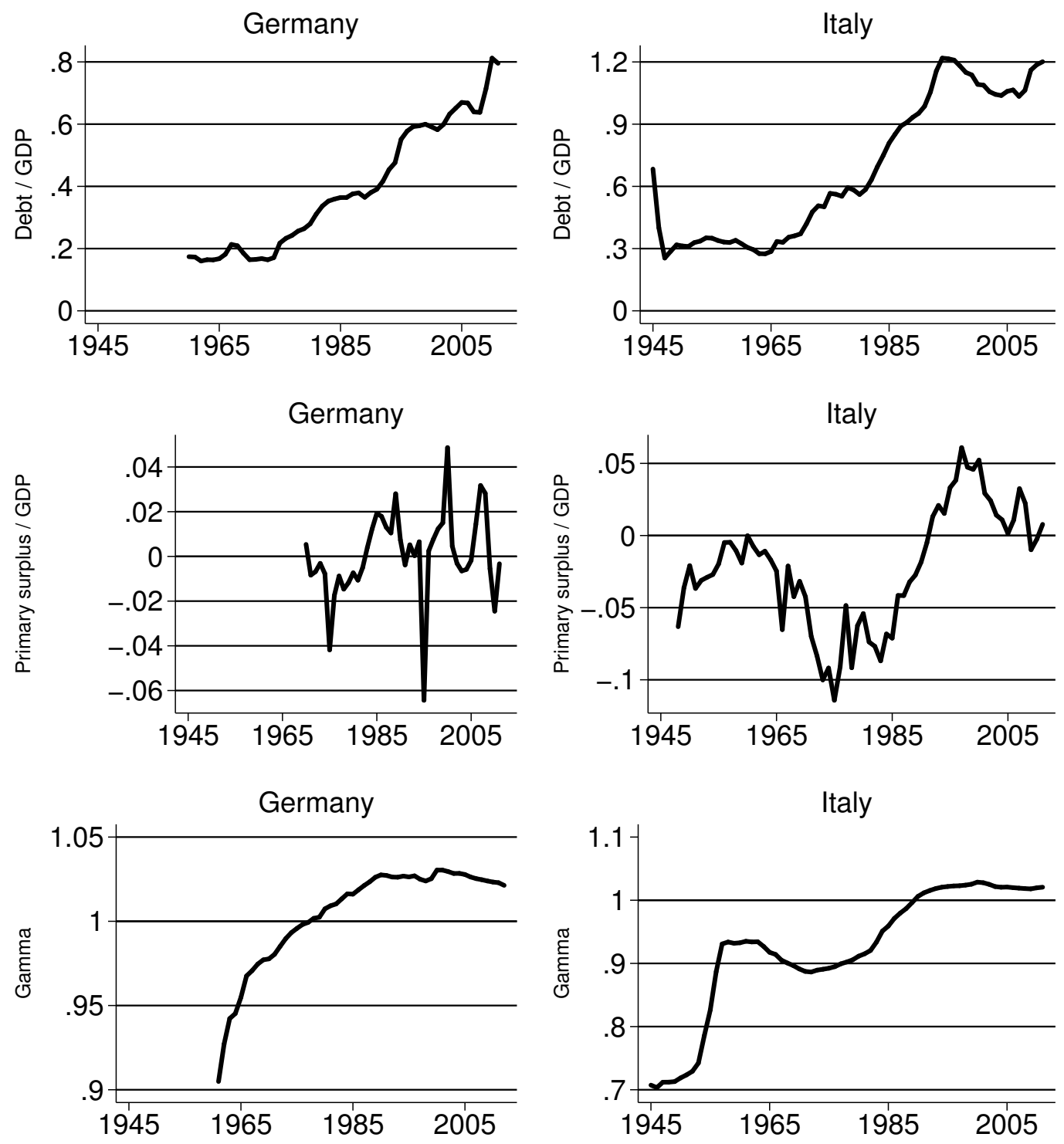

Notes: Gamma is one plus the smoothed series of the effective interest rates minus the smoothed series of nominal GDP growth rates. 
Figure 11: Spain and Portugal: Debt and primary surplus ratios to GDP, and gamma parameter, post-war samples
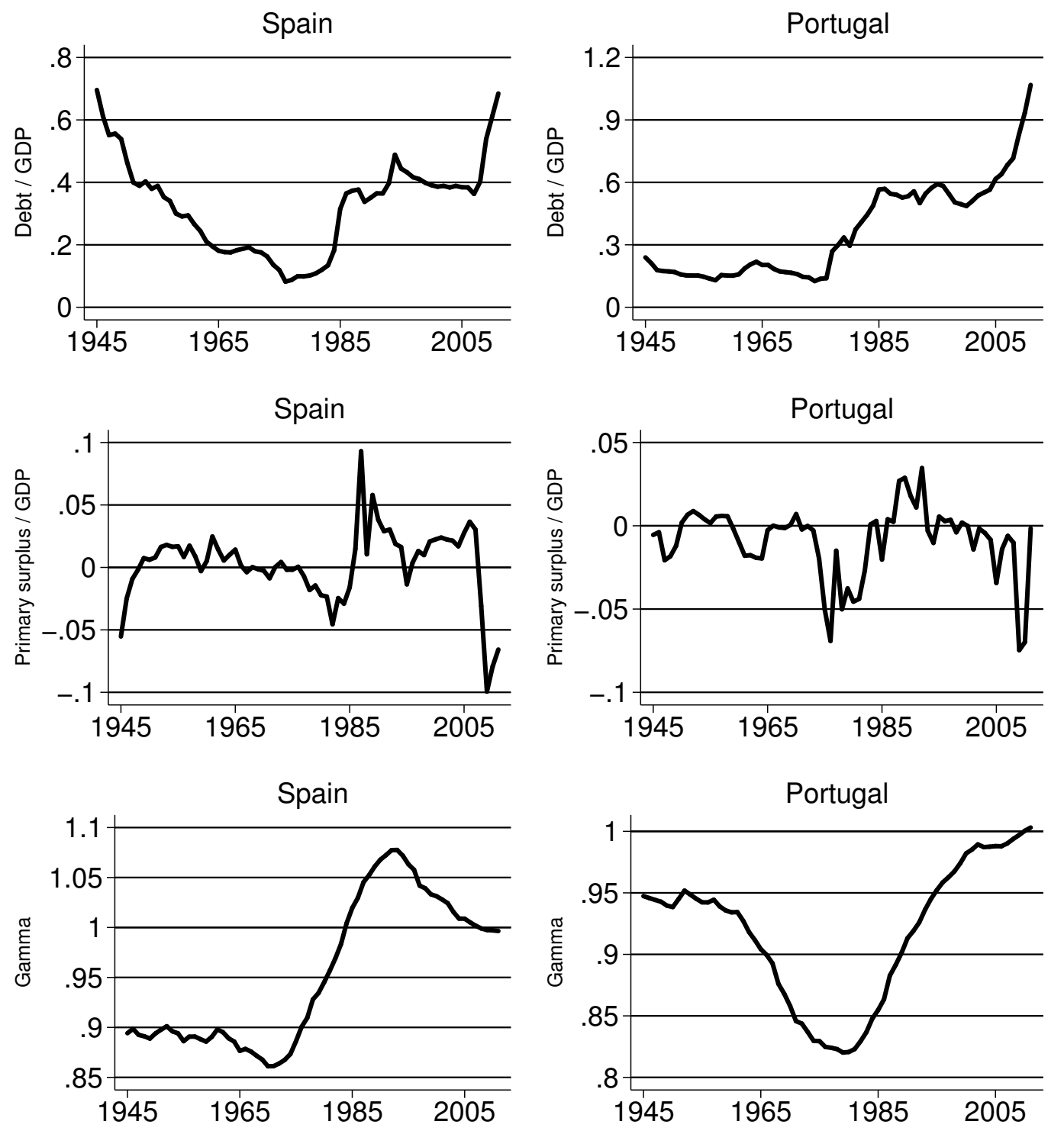

Notes: Gamma is one plus the smoothed series of the effective interest rates minus the smoothed series of nominal GDP growth rates. 
Figure 12: Iceland: Debt and primary surplus ratios to GDP, and gamma parameter, post-war sample
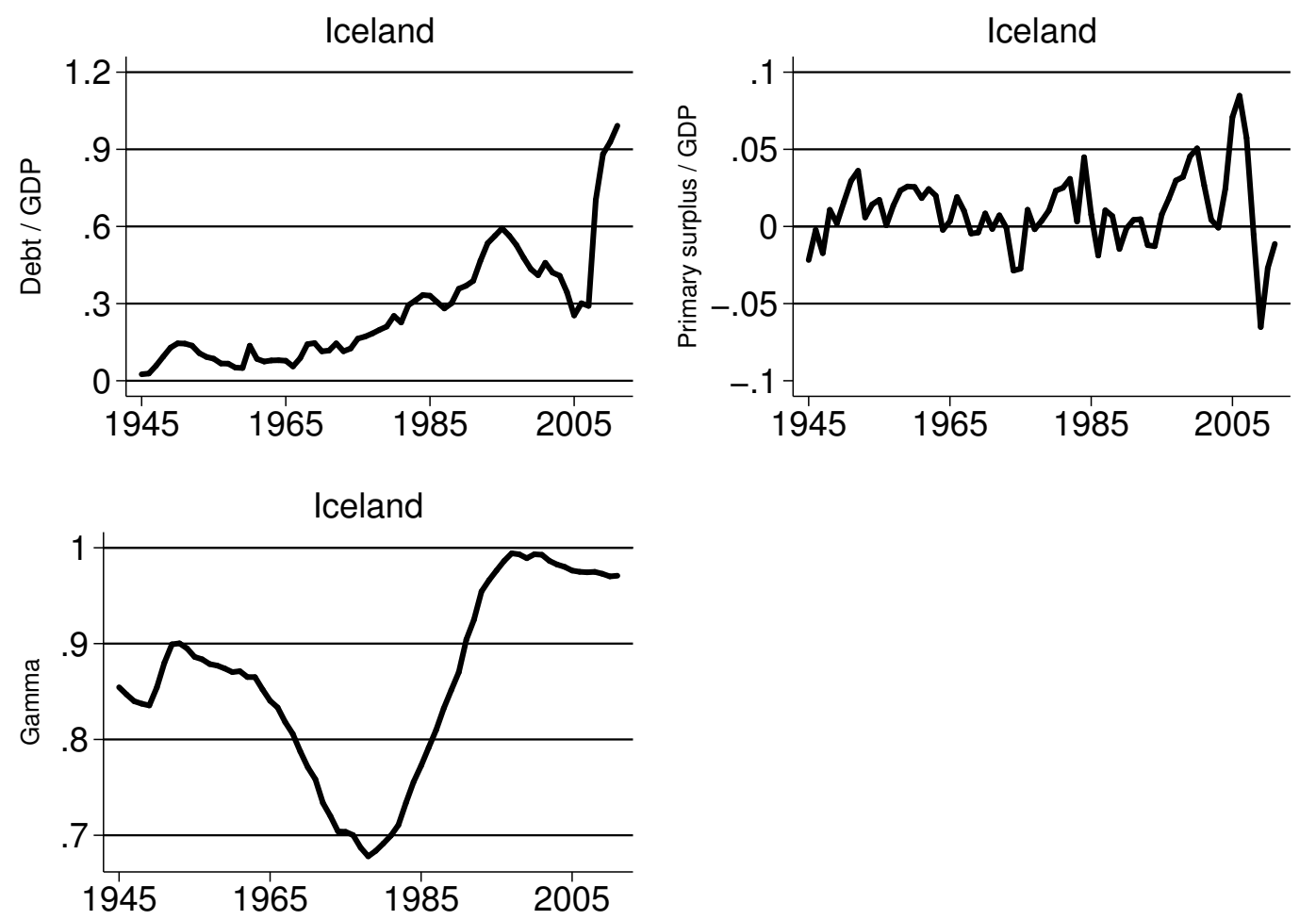

Notes: Gamma is one plus the smoothed series of the effective interest rates minus the smoothed series of nominal GDP growth rates. 